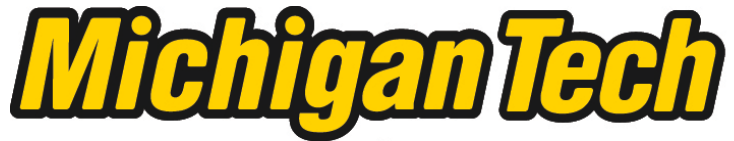 \\ Michigan Technological University Create the Future Digital Commons @ Michigan Tech
}

Dissertations, Master's Theses and Master's Reports - Open

Dissertations, Master's Theses and Master's

Reports

2015

STRUCTURAL ANALYSIS OF INTEGRATION OF A NON-

CYLINDRICAL CNG FUEL TANK

Prathamesh Prashant Deshpande

Michigan Technological University

Follow this and additional works at: https://digitalcommons.mtu.edu/etds

Part of the Computer-Aided Engineering and Design Commons, and the Energy Systems Commons Copyright 2015 Prathamesh Prashant Deshpande

\section{Recommended Citation}

Deshpande, Prathamesh Prashant, "STRUCTURAL ANALYSIS OF INTEGRATION OF A NON-CYLINDRICAL CNG FUEL TANK", Master's report, Michigan Technological University, 2015.

https://doi.org/10.37099/mtu.dc.etds/988

Follow this and additional works at: https://digitalcommons.mtu.edu/etds

Part of the Computer-Aided Engineering and Design Commons, and the Energy Systems Commons 


\title{
STRUCTURAL ANALYSIS OF INTEGRATION OF A NON-CYLINDRICAL CNG FUEL TANK
}

\author{
By \\ Prathamesh Prashant Deshpande
}

\begin{abstract}
A REPORT
Submitted in partial fulfillment of the requirements for the degree of MASTER OF SCIENCE

In Mechanical Engineering
\end{abstract}

MICHIGAN TECHNOLOGICAL UNIVERSITY

2015

(C) 2015 Prathamesh Prashant Deshpande 
This report has been approved in partial fulfillment of the requirements for the Degree of MASTER OF SCIENCE in Mechanical Engineering

Department of Mechanical Engineering-Engineering Mechanics

\author{
Report Advisor: $\quad$ Dr. Gregory M. Odegard
}

Committee Member: $\quad$ Dr. Paulus van Susante

Committee Member: Dr. Zhanping You

Department Chair: Dr. William W. Predebon 


\section{Table of Contents}

List of Figures ........................................................................................................................ V

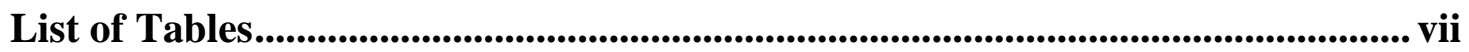

Acknowledgements................................................................................................................viii

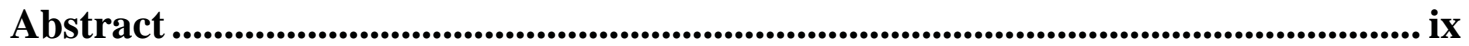

1. Introduction .......................................................................................................... 1

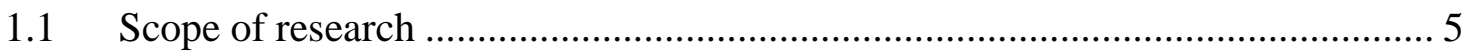

2. Geometric Modeling................................................................................................... 7

3. Computational Analysis........................................................................................ 17

3.1 Geometry cleanup and simplification ................................................................ 17

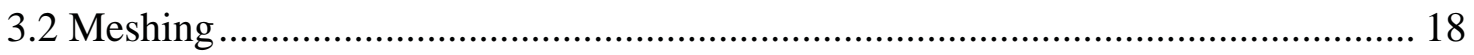

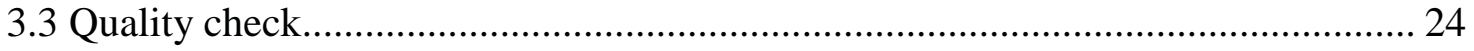

3.4 Materials and Property ………………………….......................................... 24

3.5 Load estimation for static analysis ..................................................................... 26

3.6 Forces and Constraints ................................................................................... 28

3.7 Inclusion of brackets and non-cylindrical tanks.............................................. 31

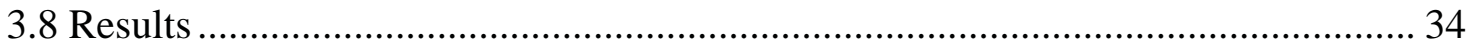

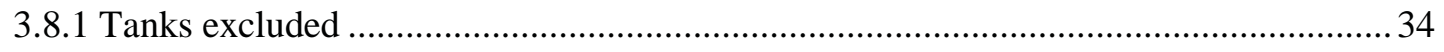

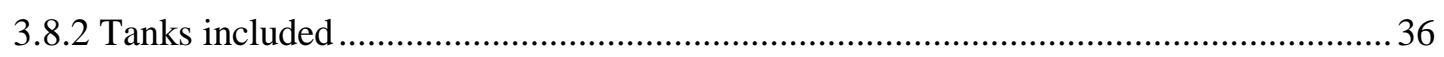

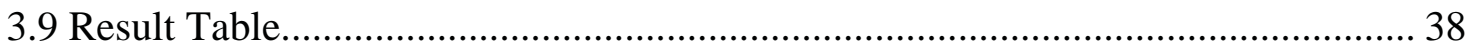

4. Discussion..................................................................................................................... 39

4.1 Original configuration .................................................................................... 39

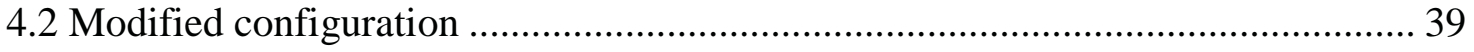

5. Conclusion................................................................................................................. 41

$5.1 \quad$ Recommendation for future work ................................................................... 41

6. References …............................................................................................................. 43 
Appendix

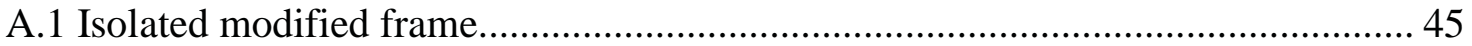

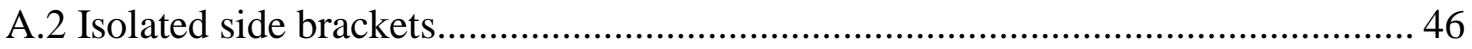

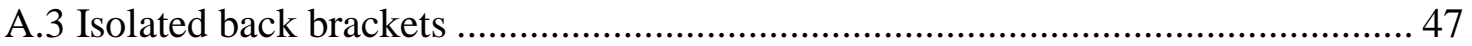




\section{List of Figures}

FIGURE 1. [UNTITLED ILLUSTRATION OF CNG POWERED PICKUP TRUCK]. RETRIEVED JUNE 22, 2015 FROM HTTP://WWW.GMFLEET.COM/VEHICLE-OVERVIEWS/FUELEFFICIENCY/BI-FUEL.HTML

FIGURE 2. CNG PACKAGING EFFICIENCY WITH REL MATRIX TANKS [ONLINE IMAGE]. (2015). RETRIEVED JUNE 22, 2015 FROM HTTP://RELINC.NET/ADVANCEDMATERIALS/CONFORMABLE-NATURAL-GAS-TANK/ .3

FIGURE 3. ODEGARD, G. M. (2015). SEVEN QUARTER SCALE TANKS POSITIONED UNDER TRUCK. RETRIEVED JUNE 22, 2015 FROM UPDATES ON CONFORMABLE TANK

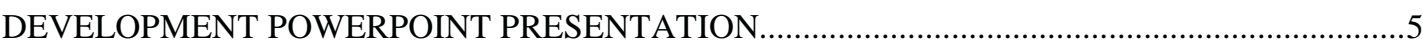

FIGURE 4. ISOMETRIC VIEW OF THE ENTIRE VEHICLE CAD 7

FIGURE 5. ODEGARD, G. M. (2015). LOANER INSPECTION. RETRIEVED JUNE 22, 2015 FROM UPDATES ON CONFORMABLE TANK DEVELOPMENT POWERPOINT PRESENTATION .....8

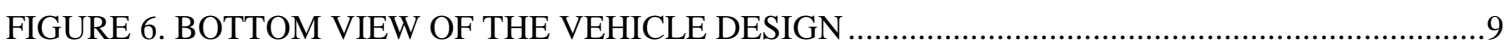

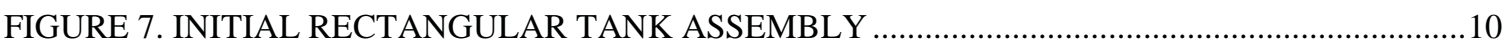

FIGURE 8. RELOCATION OF THE FUEL VAPOR CANISTER AND INCLUSION OF SMALL

LIQUID TANK ……………………...........................................................................................

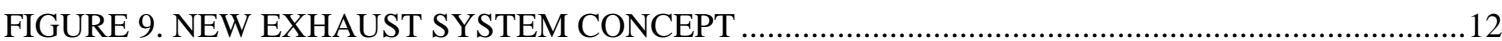

FIGURE 10. BOTTOM VIEW OF THE VEHICLE WITH MODIFICATIONS ........................................13

FIGURE 11. 2.5 INCH CELL SIZE TANK WITH ITS SECTIONAL VIEW …...........................................14

FIGURE 12. SEVEN 2.5 CELL SIZE TANKS POSITIONED ON THE VEHICLE FRAME....................15

FIGURE 13. SIDE AND BACK BRACKET DESIGN …….............................................................16

FIGURE 14. SIDE AND BACK BRACKETS MOUNTED ON THE FRAME ….....................................16

FIGURE 15. ONE OF COMPONENTS EXCLUDED FROM THE ANALYSIS ........................................18

FIGURE 16. SINGLE COMPONENT ALONG WITH ITS MID-SURFACE........................................19

FIGURE 17. ALL THE COMPONENTS ARRANGED IN THREE MAIN GROUPS ..............................20

FIGURE 18. MESH VALIDATION PLOT OF A SINGLE COMPONENT ….............................................21

FIGURE 19. DETAILED VIEW OF THE MESH PATTERN …….............................................................23

FIGURE 20. DETAILED VIEW OF THE SEAM WELD CONNECTORS USED FOR CONNECTING

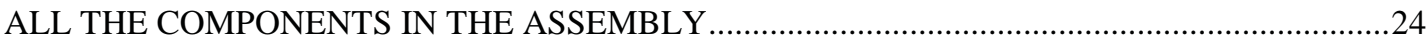

FIGURE 21. THICKNESS ASSIGNED TO THE COMPONENT USING PSHELL PROPERTY ............26

FIGURE 22. LOCATIONS WHERE THE TOTAL LOAD IS DISTRIBUTED...........................................28

FIGURE 23. BOTTOM VIEW OF THE FRAME INDICATING THE LOCATION OF CONSTRAINTS

FIGURE 24. FREE BODY DIAGRAM OF A SINGLE SIDE RAIL OF THE SYMMETRIC FRAME ....30

FIGURE 25. LAYOUT OF THE FRAME WITH BOUNDARY CONDITIONS. . .30

FIGURE 26. ALL THE THREE BRACKETS ASSEMBLED ON THE FRAME USING SPOT WELDS 32 
FIGURE 27. LOCATION OF WEIGHT DISTRIBUTION ON THE THREE BRACKETS.

FIGURE 28. DISPLACEMENT (INCH) PLOT FOR THE ORIGINAL CONFIGURATION OF THE

FRAME

FIGURE 29. VON MISES STRESS (PSI) PLOT FOR THE ORIGINAL CONFIGURATION OF THE

FRAME

FIGURE 30. DISPLACEMENT (INCH) PLOT OF THE FRAME WITH MODIFIED CONFIGURATION

FIGURE 31. VON MISES STRESS (PSI) PLOT OF THE FRAME WITH MODIFIED CONFIGURATION

FIGURE 32. DISPLACEMENT (INCH) PLOT OF THE ISOLATED FRAME WITH MODIFIED CONFIGURATION .45

FIGURE 33. VON MISES STRESS (PSI) PLOT OF THE ISOLATED FRAME WITH MODIFIED CONFIGURATION

FIGURE 34. DISPLACEMENT (INCH) PLOT OF THE ISOLATED SIDE BRACKETS ......................46

FIGURE 35. VON MISES STRESS (PSI) PLOT OF THE ISOLATED SIDE BRACKETS ......................46

FIGURE 36.DISPLACEMENT (INCH) PLOT OF THE ISOLATED BACK BRACKET ......................47

FIGURE 37. VON MISES STRESS (PSI) PLOT OF THE ISOLATED BACK BRACKET. 47 


\section{List of Tables}

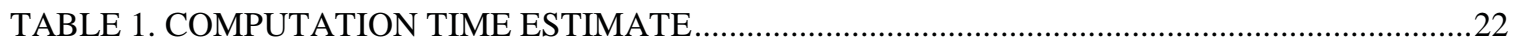

TABLE 2. MATERIAL PROPERTIES OF GM 980X HSLA STEEL (RASHID, 1977) .............................25

TABLE 3. MATERIAL PROPERTIES OF A36 MILD STEEL (MATWEB, LLC, 2015) ..........................32

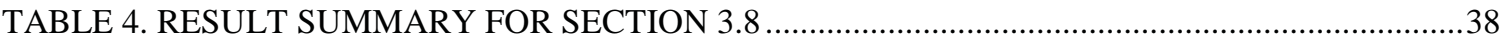




\section{Acknowledgements}

I would like to thank my advisor Dr. Gregory M. Odegard, Associate Chair and Director

of Undergraduate Studies, Department of Mechanical Engineering - Engineering Mechanics, for giving me the opportunity to work with him. His valuable support, expert knowledge and motivation has helped me become a better engineer and a better individual.

I would like to thank Dr. Paulus van Susante and Dr. Zhanping You for their valuable time and feedback for my report. Also I would like to say thank you to Dr. Jeremy Worm for sharing his expert knowledge in automotive engineering.

I would like to convey my appreciation to my colleagues Amruta Kulkarni, Paul Roehm, Adit Manurkar, Cayman Berg-Morales, Yomi Famuyiwa and Zongyue Liu. I would also like to thank Madhu Kolati, Sachin Shinde and Abhilash Shankar for their crucial tips on the analysis and report. 


\begin{abstract}
The purpose of this study is to computationally model and analyze the vehicle frame which is mounted with a non-conventional, non-cylindrical compressed natural gas (CNG) fuel tank. Integration of this tank in the vehicle underbody will resolve the issue of reduced storage space which is observed in a conventional CNG powered vehicle. This research will ultimately result in making CNG a good alternative to gasoline and reducing the increasing dependency on a single fuel. This tank will be developed in two phases: phase I design of the tank will be a standard rectangular outer box shape with Schwarz P-surface inner structure and phase II will be a complex and conformable shaped tank. This study will only include phase I tanks and the only load case considered is a simple linear static case. Modifications are made to the vehicle frame using a computer aided design (CAD) software in order to accommodate the tank. The results obtained from the finite element analysis of the frame support the design modifications made to the frame and shows the ability of the frame to handle a heavier tank.
\end{abstract}




\section{Introduction}

Gasoline is widely used as a primary fuel for automobiles. Due to its stable performance and well established maintenance infrastructure, introduction of alternative fuels has very little effect on consumer choice. The United States of America produces most of the consumed gasoline. However increasing dependency on a single fuel has resulted in gasoline imports and rise in fuel prices (Kilian, 2010).

Compressed Natural Gas, or CNG, is one of the alternative fuels which is being used in some automobiles for applications such as public transport buses, private transportation trucks, waste management vehicles and other similar services. The USA produces CNG domestically. Due to less consumption in comparison to gasoline, CNG is considered to be a good alternative fuel (Ahn, Jeong, \& Kim, 2008). The experimental study of CNG as an automobile fuel shows that in comparison with gasoline, there is a considerable drop in vehicular emissions such as carbon monoxide ( $80 \% \mathrm{CO})$, carbon dioxide $\left(20 \% \mathrm{CO}_{2}\right)$ and hydrocarbons ( $\left.50 \% \mathrm{HC}\right)$. Also under common conditions the fuel consumption (BSFC) is reduced by 17-18\% (Aslam et al., 2006).

Because of its gaseous state, storage of CNG is an important fuel tank design parameter. As the name suggests the fuel needs to be stored under pressure in order to obtain effective combustion of fuel. Cylindrical shape provides both a robust structure and a geometry assisting streamline flow. CNG tanks available in market today, come in cylindrical shape with spherical heads which helps regulate uniform gas pressure. 


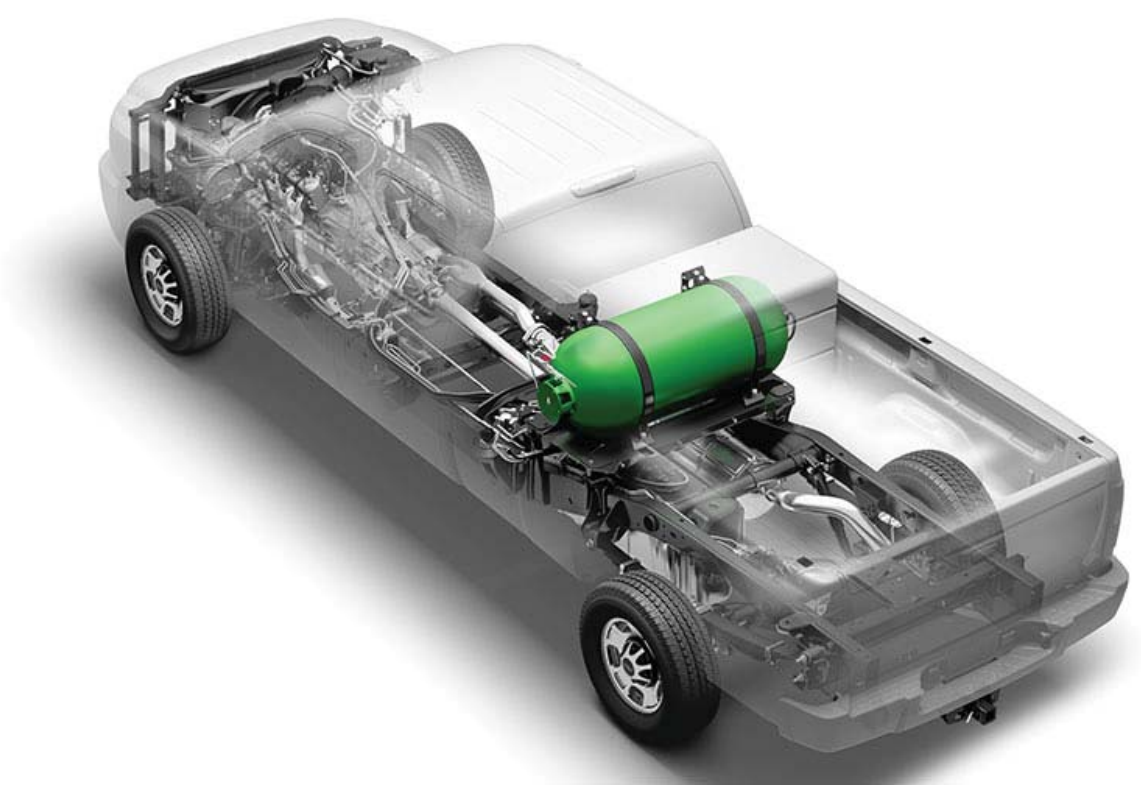

Figure 1. [Untitled illustration of CNG powered pickup truck]. Retrieved June 22, 2015 from http://www.gmfleet.com/vehicle-overviews/fuel-efficiency/bi-fuel.html

Figure 1 shows the conventional CNG tanks that are currently being used. Even though the cylindrical tanks used today are performing well, they come with certain limitations that makes the customer avoid buying CNG fueled vehicles. CNG refueling stations are not that commonly seen as compared to the gasoline stations. Although the CNG fuel infrastructure is slowly developing, the CNG fueled vehicles have the fuel tank situated in the bed or cargo. This is because the cylindrical shape cannot be accommodated in the underbody of the vehicle. The space available in the underbody proves sufficient for a conventional liquid fuel tank with the same capacity. The liquid fuel can be burnt at atmospheric pressure and pre-pressurization is not required, hence the conventional tanks are conformable and designed to fit in the underbody consisting of varying contours. Capacity requirement for a gaseous fuel is measured in gasoline gallon equivalent (gge). The meaning of 1gge is the amount of gasoline consumed to cover the same distance as achieved by consumption of 1gallon of gasoline. In order to meet the driving range the 
current liquid tanks provide, the size of the cylindrical fuel tanks must come in large sizes, which have to be accommodated in the bed or cargo of the vehicle.

Vehicles such as the light weight pickup trucks attract consumers who are looking for large storage space. Presence of a large fuel tank in the cargo space is a big turn off for a customer. The tank almost takes one third of the available storage space thus diminishing the purpose of the pickup trucks. It is essential to attract customers towards CNG powered vehicles to reduce dependence on gasoline.

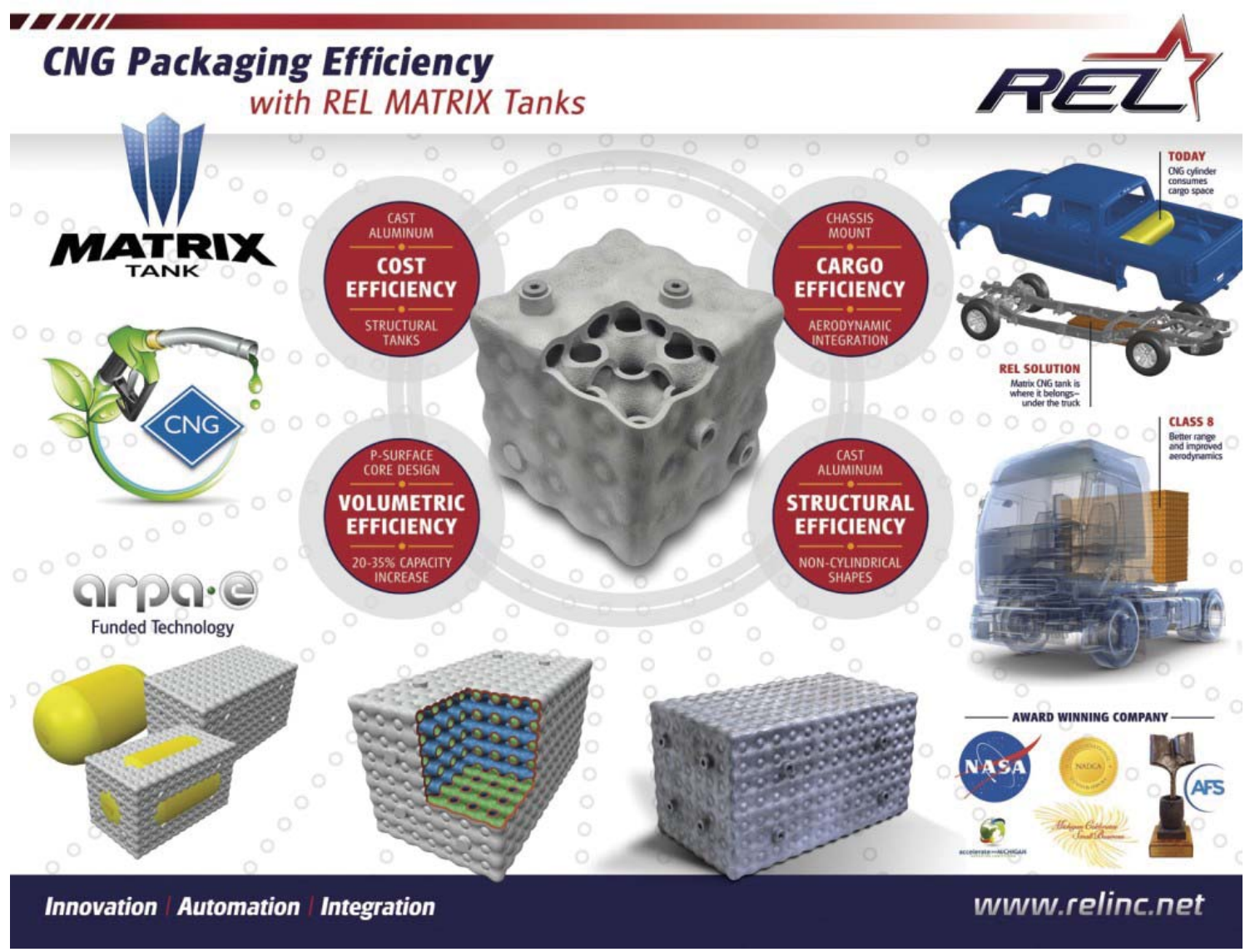

Figure 2. CNG Packaging Efficiency with REL MATRIX Tanks [Online Image]. (2015). Retrieved June 22, 2015 from http://relinc.net/advanced-materials/conformable-natural-gas-tank/

Named after founder Robert E. Loukus, B.S. Mechanical Engineering, REL Inc. from Calumet, MI has developed the non-cylindrical CNG fuel tank design matching the 
conventional CNG tank in terms of fuel handling capacity and performance. The tank has a unique inner structure similar to sea urchin skeleton also known as the Schwarz P-surface. There are spherical cells integrated in a rectangular shaped outer body thus eliminating corners in the geometry. Figure 2 shows the structure of these tanks along with potential mounting solutions. This tank is capable of getting mounted on the vehicle frame thus resolving the storage space issue. The challenge with development of this tank is use of appropriate material for tank fabrication, mounting this tank on the vehicle and performance of the tank under varying driving situations. The material should be light weight considering the complex inner structure and weight carrying capacity of the vehicle frame and it should sustain the rated pressure of the gaseous fuel.

Southwestern Energy Company, REL Inc. and Michigan Technological University (MTU) have collaborated to develop and integrate this unique tank design on a 2015 Chevrolet Silverado pickup truck. This project, considering its wide scope, is divided into two phases with the span of total three years. Phase I consists of development of these noncylindrical tanks in simple rectangular box type outer shape. Within this phase, the rectangular tanks will be mounted in the vehicle underbody with the help of a suitable mounting assembly and modification of the default underbody structure. Figure 3 shows the probable layout of these tanks on a pickup truck. The underbody of an automobile mainly consists of the powertrain, drive shaft, differential assembly, exhaust system, liquid fuel tank, and spare tire. In order to mount the non-cylindrical tank these assemblies may require redesigning and relocating. 


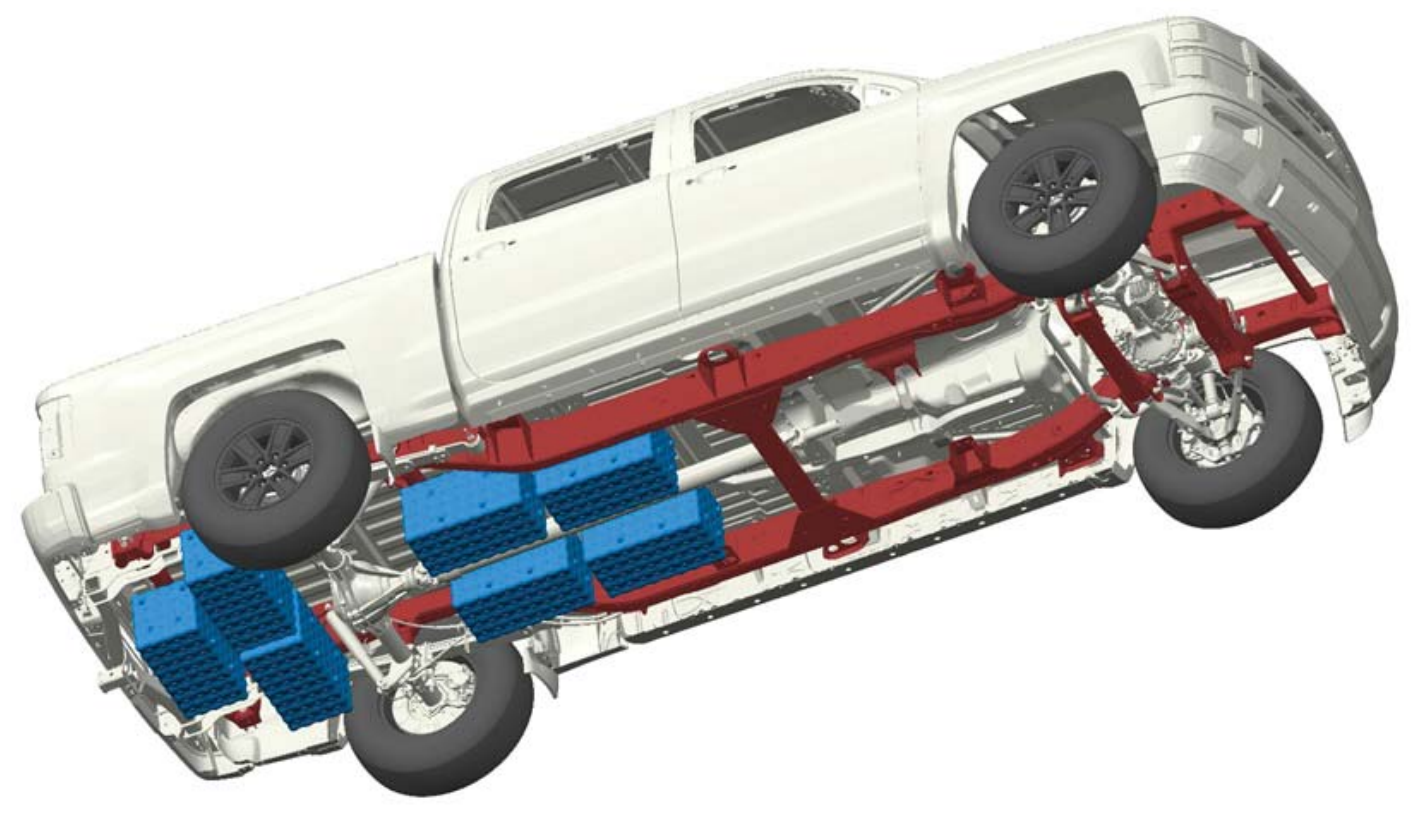

Figure 3. Odegard, G. M. (2015). Seven quarter scale tanks positioned under truck. Retrieved June 22, 2015 from Updates on Conformable Tank Development PowerPoint presentation

\subsection{Scope of research}

This project will be conducted in two distinct phases. Phase I will be development of the non-cylindrical CNG tanks with standard rectangular outer box shape with Schwarz P-surface inner structure. The main goal of this phase is to mount these tanks and make the vehicle run on CNG fuel. The actual tests performed in this phase will include driving the vehicle on a plane road with standard bumps and potholes, off-road testing and overloading of the cargo will not be tested. Phase II will include a refined outer box design which will be conformable in shape. The scope of this study will not include phase II tanks and dynamic analyses.

This study will help establish whether multiple number of heavy tanks can be mounted on a regular pickup truck frame. Also the stress plots generated after analysis, will indicate the potential low stress regions on the frame which can be utilized for 
employing modifications accompanying mounting of these tanks. This study includes computational techniques used to analyze the computer aided design of the frame in a static load case, which includes the frame in static position with loads acting due to weight of the vehicle sub-assemblies. The analysis will not include the dynamic cases like impact tests (front, rear or side), optimization (thickness or shape) or non-linear cases (contacts or material). 


\section{Geometric Modeling}

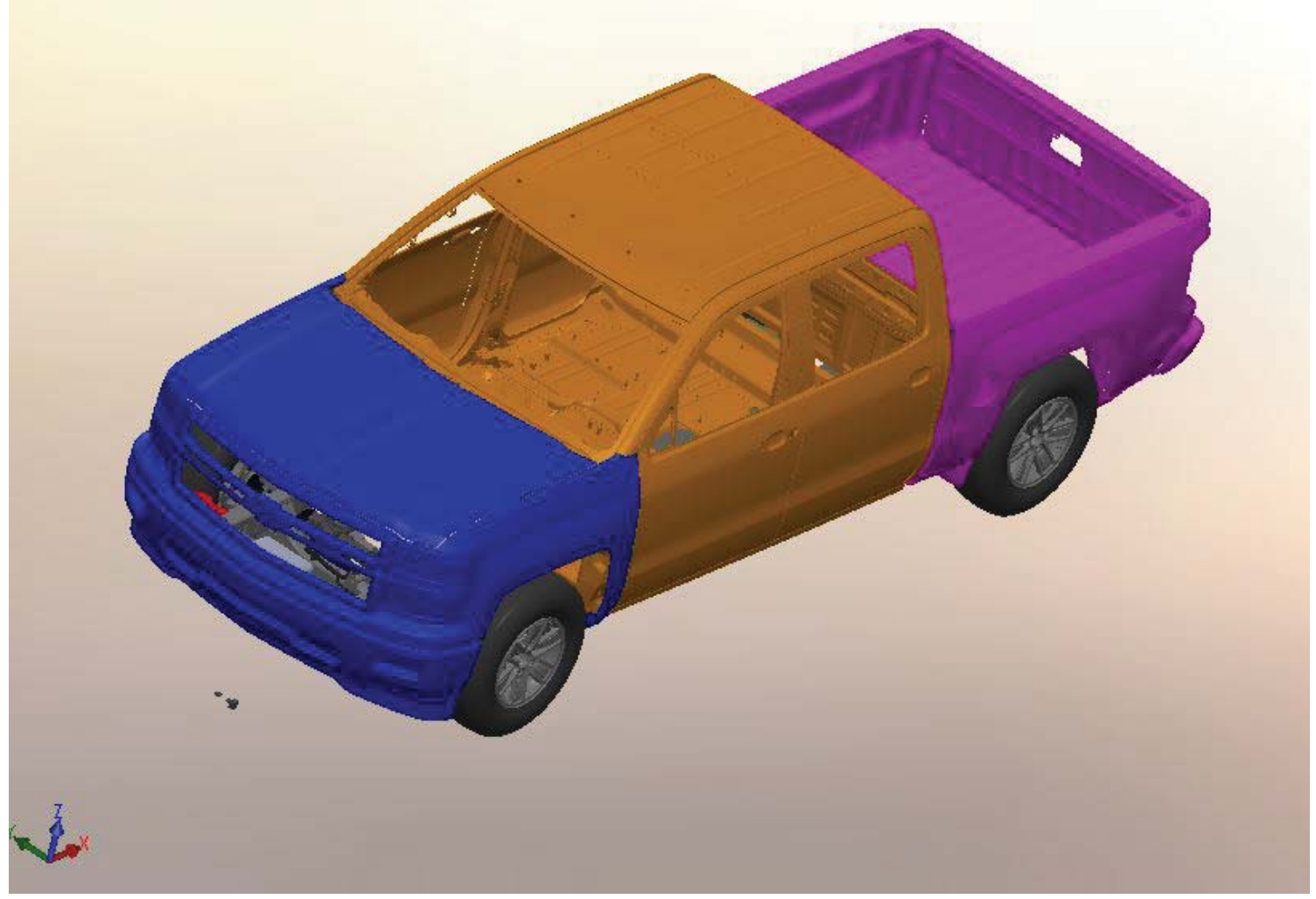

Figure 4. Isometric view of the entire vehicle $C A D$

A three dimensional computer aided design (CAD) of the 2015 Chevrolet Silverado 1500 Double Cab Standard box pickup truck consisting of all the significant assemblies was provided by REL Inc. The model was an assembly file which consists of the various sub-assemblies. Figure 4 shows the isometric view of the CAD. Some sub-assemblies were absent from the model file. The reason for this was not provided and work was continued on it since the area under observation was replicated accurately. The important missing parts were the main driveshaft connecting front and rear axles, the powertrain assembly and its mounting bracket assembly, the engine and its sub-components, and the liquid fuel tank and its sub-components. The mounts for the main vehicle body and cargo were present in the model along with the crucial cross-members connecting the side rails of the frame. 


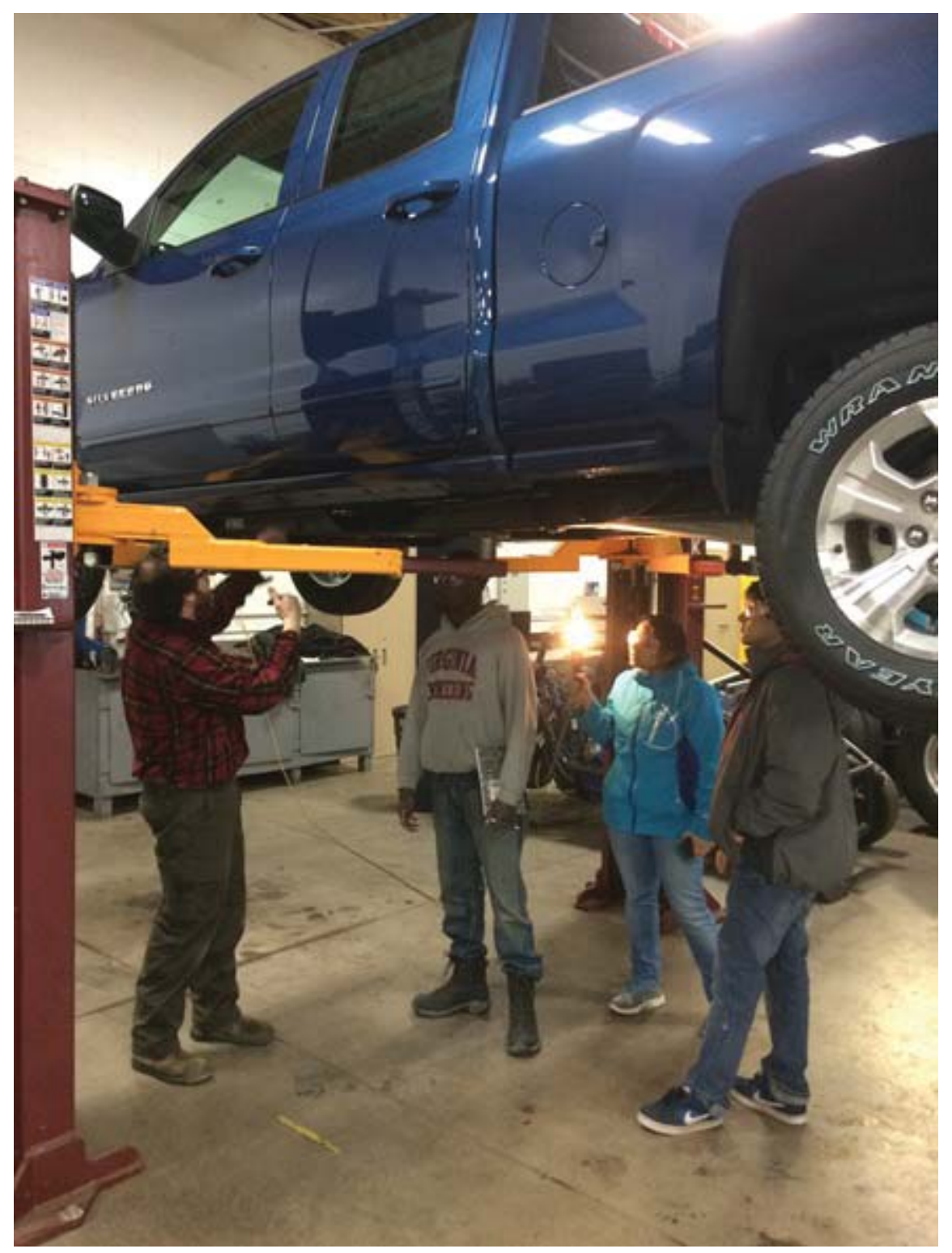

Figure 5. Odegard, G. M. (2015). Loaner inspection. Retrieved June 22, 2015 from Updates on Conformable Tank Development PowerPoint presentation

A substitute Silverado 1500 truck was borrowed from a dealer in Calumet, MI in order to examine the underbody of the vehicle. Figure 5 shows the actual inspection which helped gain a better view of the area under study. This opportunity was used to locate the missing components in the CAD file. Also a record was made of the most promising modifications for integration of the non-cylindrical CNG tank. The most pivotal modifications were: removal of the spare tire, relocation and redesign of the exhaust 
system, and removal of the liquid fuel tank. The area vacated by these components would be used to accommodate the rectangular tanks. The requirement of mounting more than one non-cylindrical tank was established because of the fuel carrying capacity of these tanks. Due to the dense inner structure, the volume carried by a single tank is not sufficient to run a vehicle for long distances. An estimate was made of mounting a total of three tanks on the chassis. Also a small aftermarket liquid tank was to be mounted near the drivetrain as a source of secondary fuel.

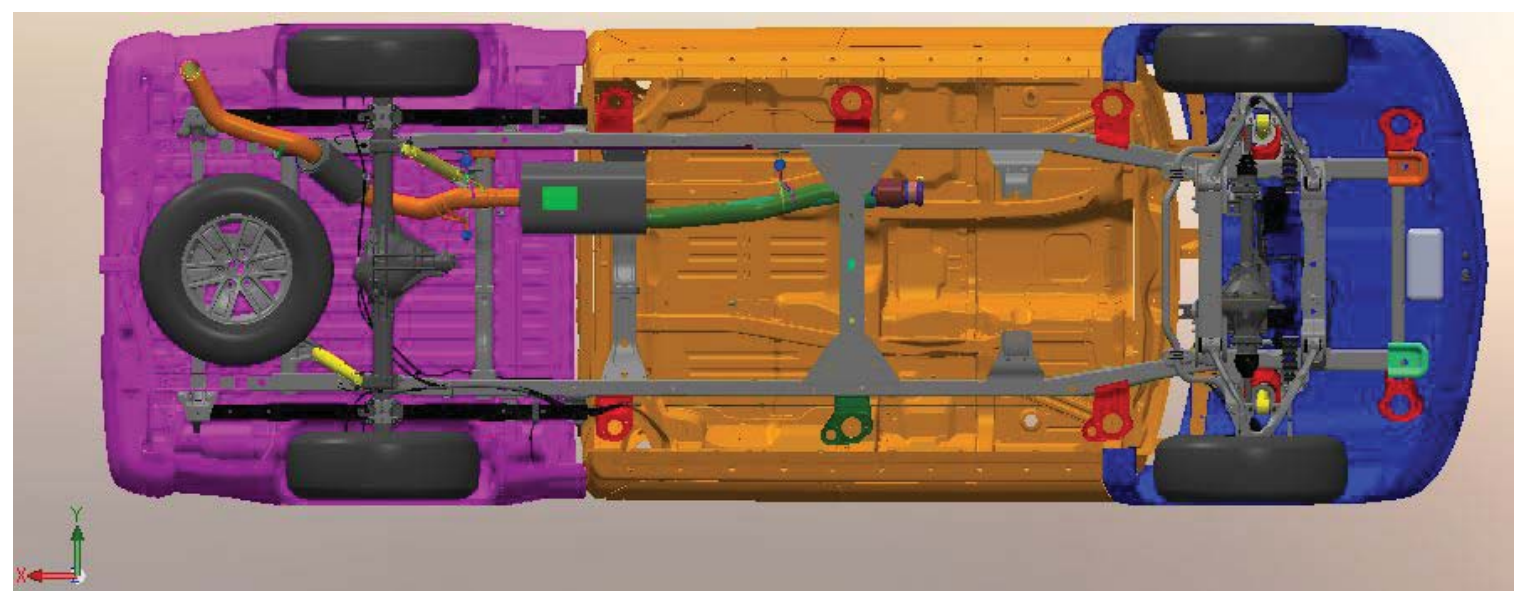

Figure 6. Bottom view of the vehicle design

The original CAD model did not include the liquid fuel tank and driveshaft, so that space was used to position the rectangular tanks. Figure 6 shows the missing parts from the CAD file. Measurements of length, width and height of the volume accommodated by the liquid tank were recorded during the inspection. The dimensions of the space taken by the liquid gas tank were 41 inches x 14 inches x 12 inches. The liquid fuel tank is accompanied by a fuel vapor canister which is linked to the tank in series connection. The role of the vapor canister is to absorb the vapors from the fuel tank and supply it to the engine, thus avoiding emissions of the evaporated fuel. This part can be moved as it has no locational requirement. Hence to get access to some extra space this canister was to be relocated in 
the front crash zone. The reason for this was that even in the case of any hazard the canister will not burst. This modification created an extra longitudinal space of 14 inches. A CAD part file of the rectangular tank was created using Solidworks 2k13 geometric modeling software. It was a simple rectangular box which was assembled in the space where the liquid tank was present. The dimensions of the box are 55 inches x 14 inches x 12 inches. Figure 7 shows the three assembled rectangular tanks. Figure 8 shows the fuel vapor canister relocated in the front crash zone and the secondary liquid fuel tank.

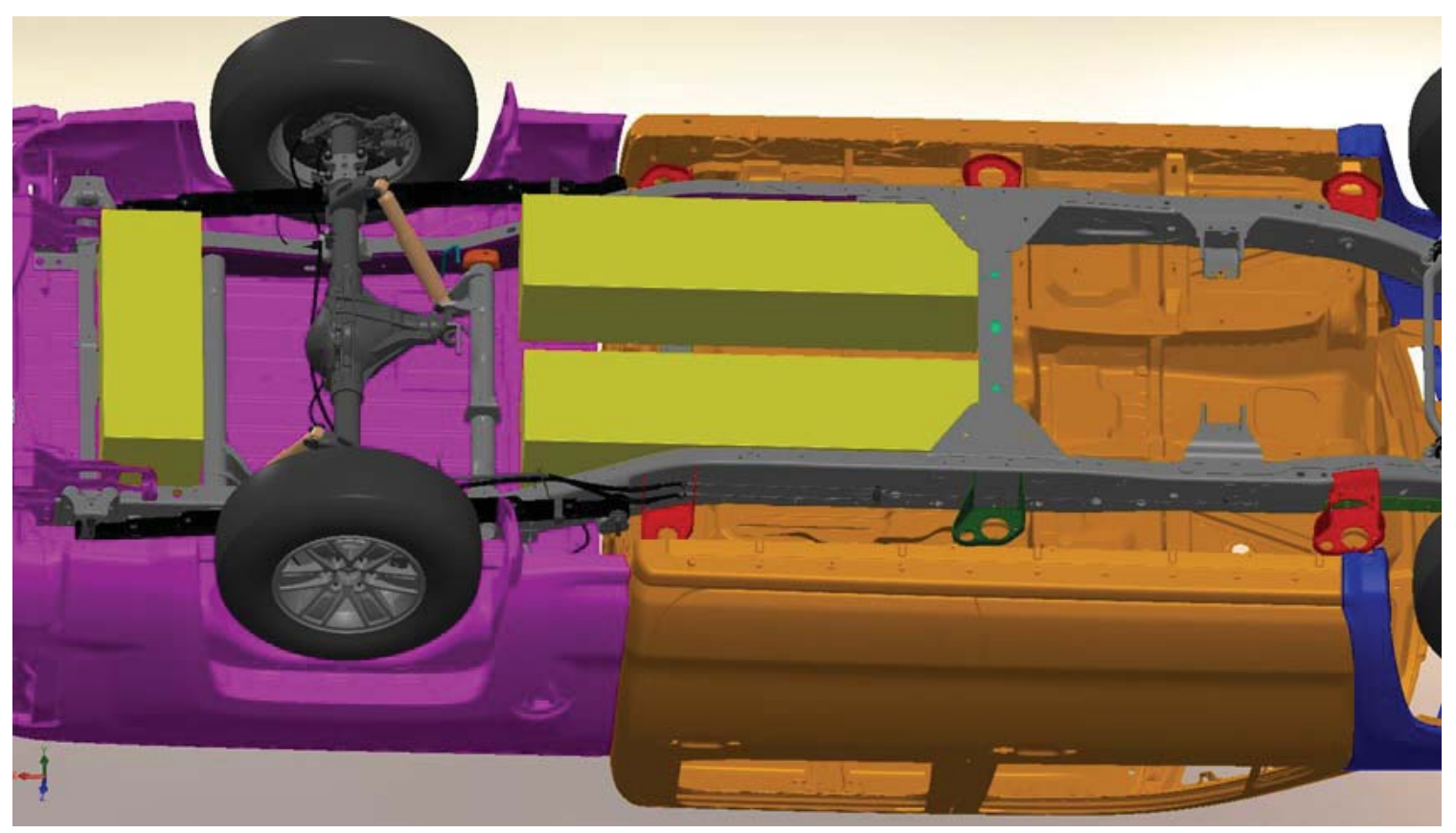

Figure 7. Initial rectangular tank assembly 


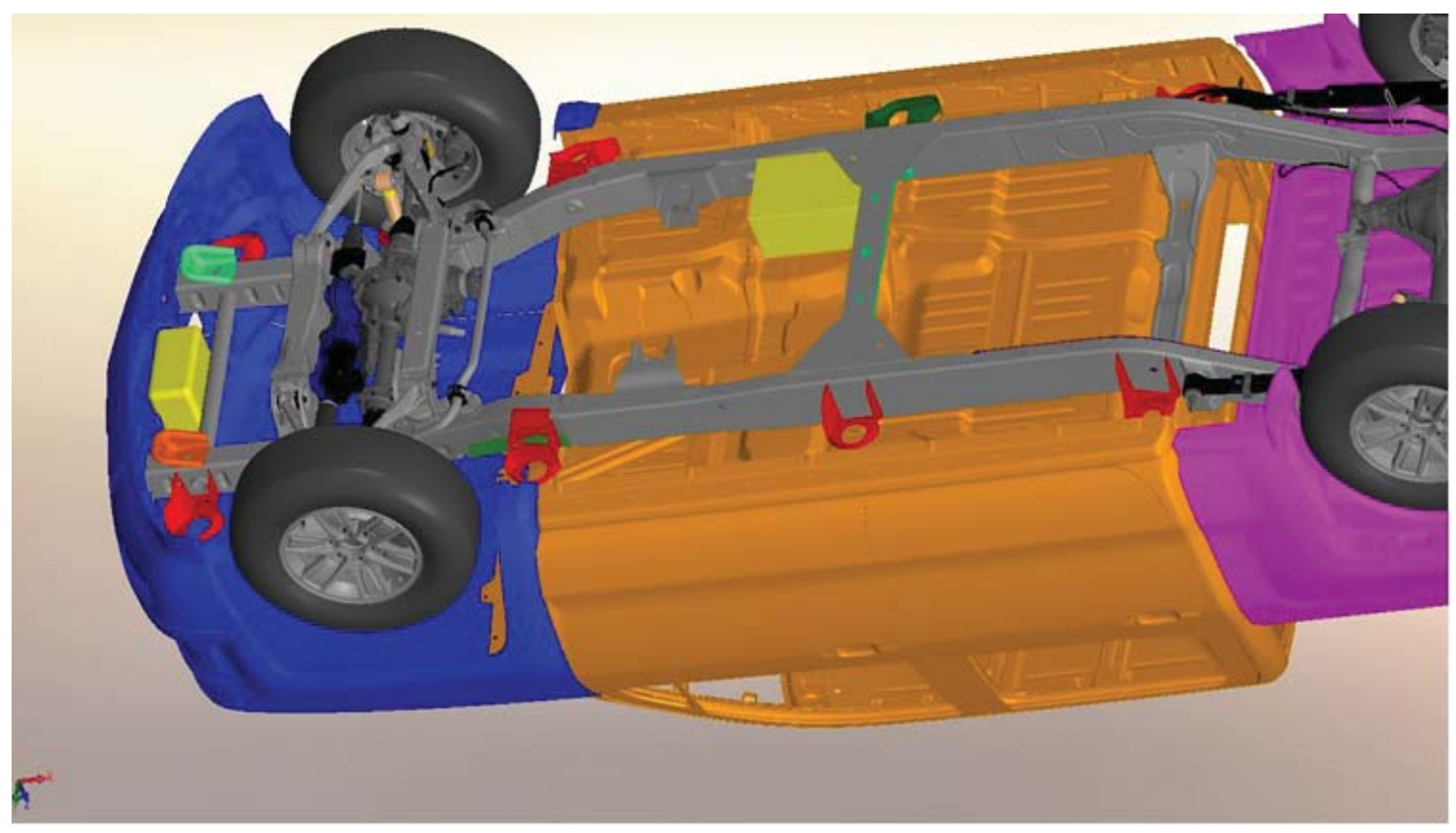

Figure 8. Relocation of the fuel vapor canister and inclusion of small liquid tank

The current exhaust system occupies the entire passenger side space. It is essential to change the exhaust system's location as more than one non-cylindrical tank is to be mounted on the frame. As the exhaust assembly consists of a flex pipe, a muffler, a resonator and an exhaust gas pipe, it covers very little volume. Hence it can be relocated and redesigned to accommodate less area. The exhaust assembly was totally removed from the CAD model and replaced by another rectangular tank which was the mirror image of the tank occupying the liquid tank space. The new exhaust system is currently being designed by the integration team at the Advanced Power Systems (APS) Labs, in Calumet. The new system will contain side exhaust pipes, and the original mufflers will be replaced with the small sized mufflers, as shown in Figure 9. 


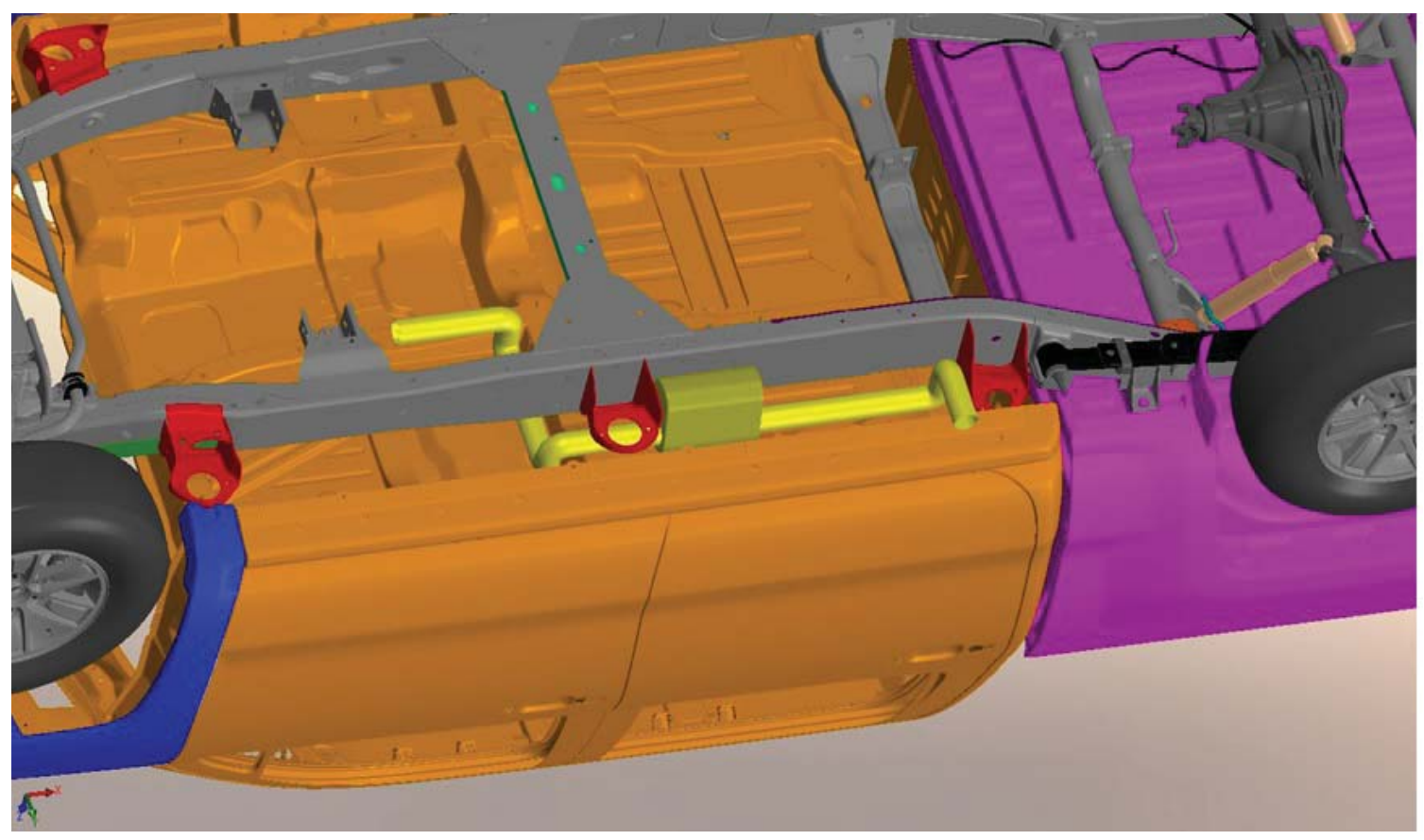

Figure 9. New exhaust system concept

Unlike the exhaust system it is not possible to relocate the spare tire since it has a large volume. Also, it is one of the important requirements of a customer to get a vehicle with a spare tire. However for the phase I of the project the spare tire was to be removed. The space made available due to this modification was 13 inches x 36 inches x 19 inches. Using these dimensions the third rectangular tank was modelled and assembled in the spare tire space, as shown in Figure 7 . Figure 10 shows the total modifications that were initially decided. 


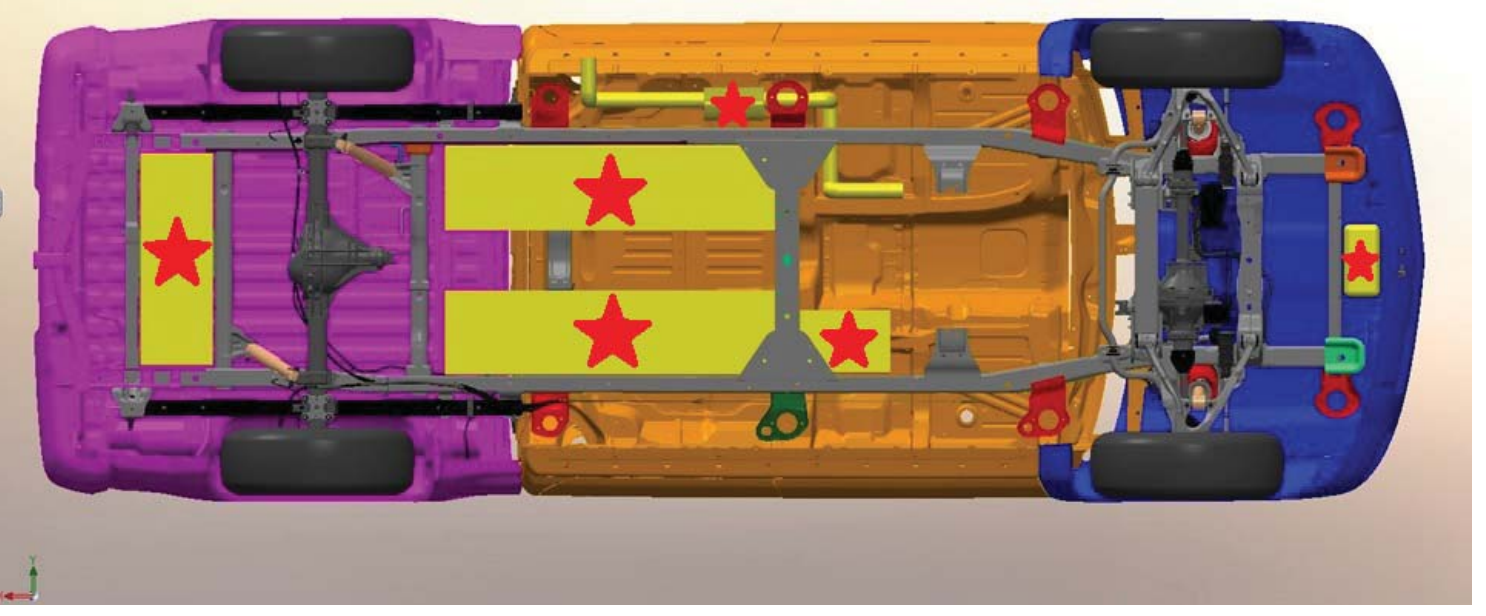

Figure 10. Bottom view of the vehicle with modifications

The three rectangular tanks were modelled with the help of the dimensions of the space made available by the removed assemblies. There were certain problems generated due to the initial modifications. The underbody of the vehicle had varying contours on which the default liquid fuel tank was conformed and fit. The rectangular tanks had plane surfaces and hence they were mounted to hang lower than the original tank, reducing the clearance level of the vehicle. Another crucial point was the mounting assembly for the rectangular tanks. The existing body and cargo mounts were designed to handle lightweight thin plastic tanks, whereas the rectangular tanks were dense and bulky. Hence designing a robust, custom-made bracket is essential to mount these tanks. From the manufacturing point of view, fabrication of three unique rectangular tanks is not possible when it comes to batch production. The challenges faced are designing the inner cell sizes and new molds for casting of three individual tanks. Hence it was important to come up with a design such that standard dimensions were employed and production of the tanks was made easy. REL Inc. came up with the standard dimensions of 22.25 inches $\mathrm{x} 12.24$ inches $\mathrm{x} 11.6$ inches for the tanks. Figure 11 shows the CAD model of these tanks. 

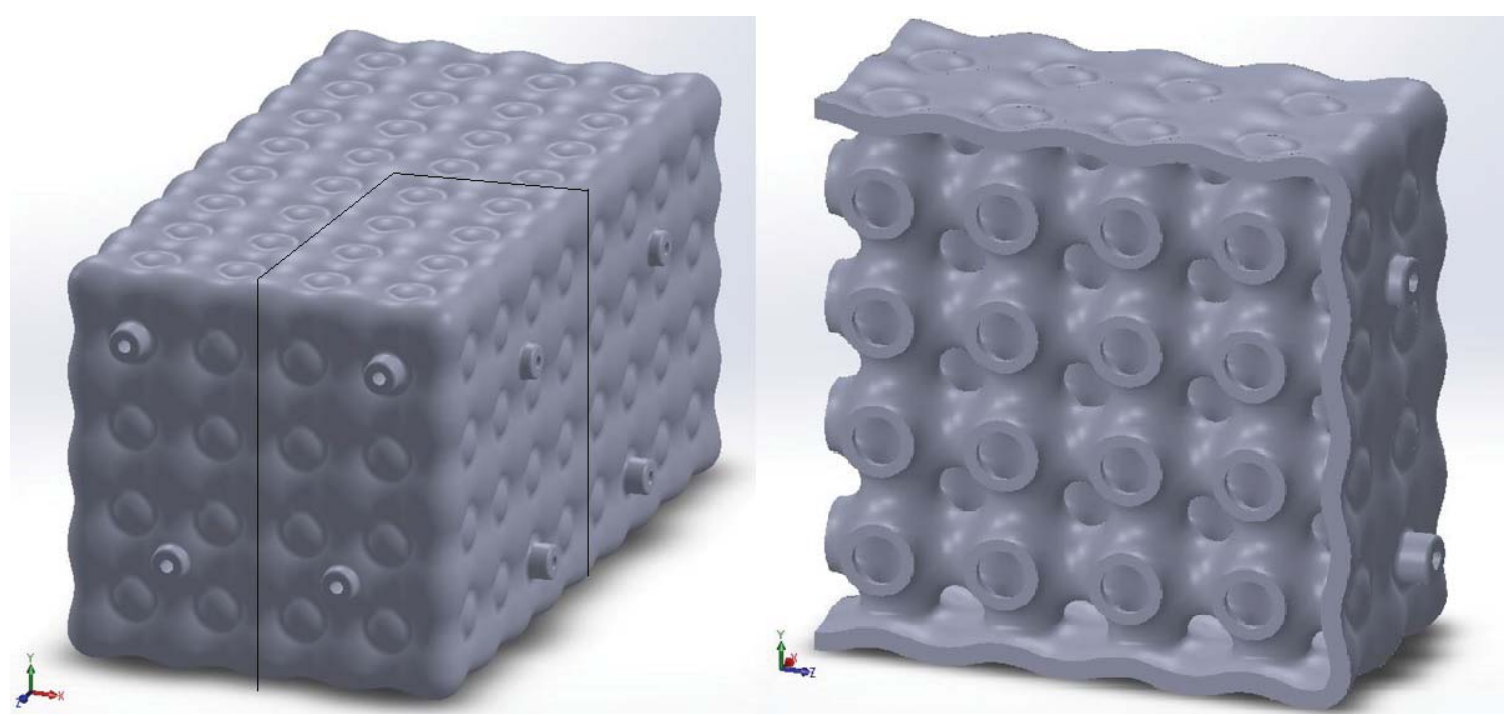

Figure 11. 2.5 inch cell size tank with its sectional view

The conventional liquid fuel tank has the capacity to hold 26 gallon of gasoline in the Silverado 1500 truck. Therefore for achieving the driving range close to 26 gge fuel, seven standard tanks were to be mounted on the vehicle, each tank having the capacity of 3 gge. The layout of the seven tanks mounted on the truck was generated by the CAD specialist at REL Inc. With the help of the layout, first the frame was isolated and the three initial tanks were replaced by the seven boxes of equal dimensions as the tanks. The purpose was to make the CAD simpler for the analytical software. Figure 12 shows the layout of the frame with seven tanks mounted on it 


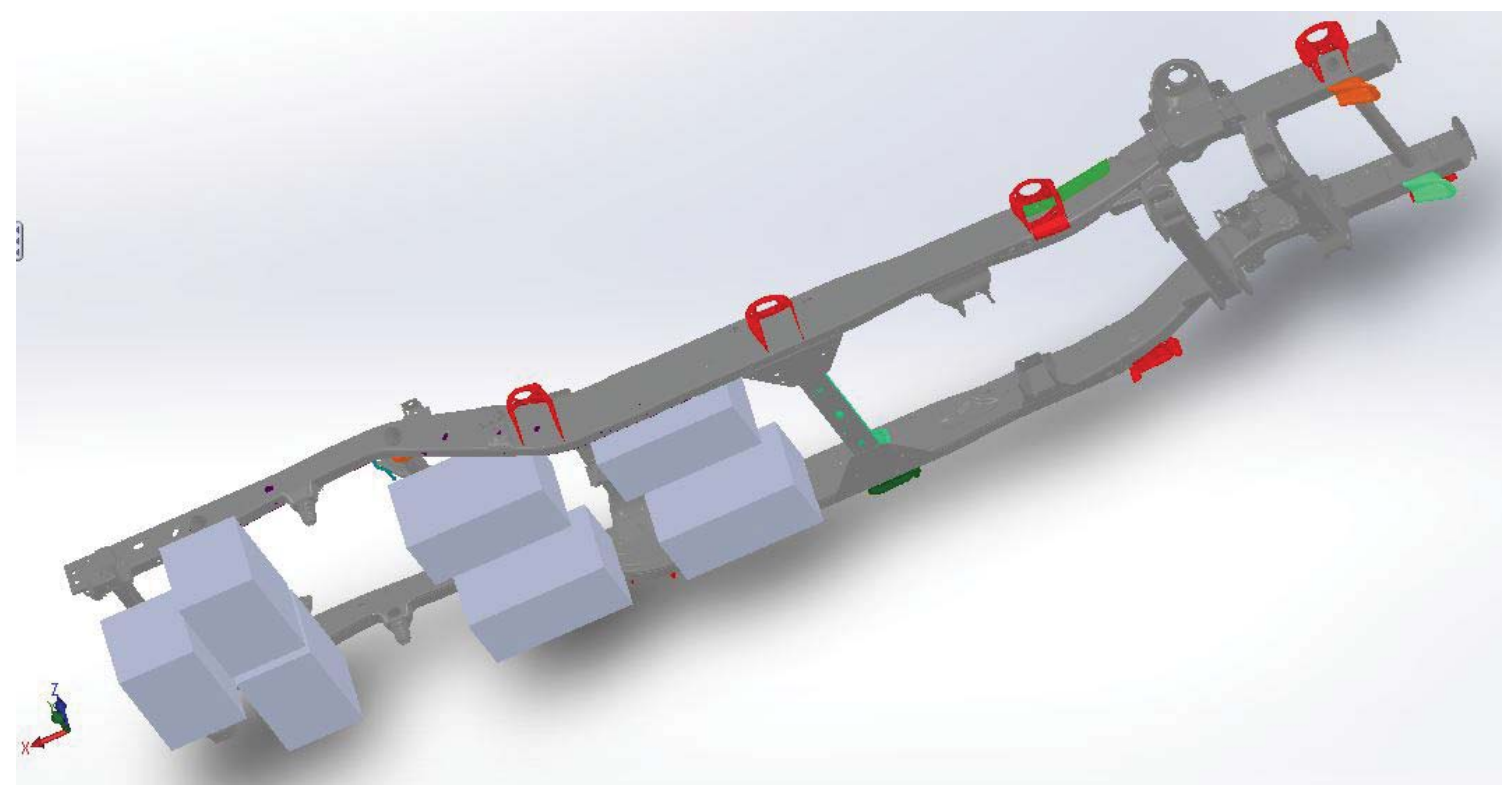

Figure 12. Seven 2.5 cell size tanks positioned on the vehicle frame

The mounting of the seven tanks was to be done using custom designed brackets. A total of three brackets was to be designed for carrying all the tanks. Simple C-channels were used and the design was optimized using finite element method. The brackets were to be bolted on the frame and cross members. The 3D design of these brackets was performed by Cayman Berg-Morales, Third Year Undergraduate student, Mechanical Engineering, MTU and the Finite element Analysis of the individual brackets was performed by Paul Roehm and Adit Manurkar, both First Year Graduate students, Mechanical Engineering, MTU. Currently two brackets, for tanks located in place of the exhaust system and in the place of the spare tire, have been designed and are being optimized. Figure 13 shows the two mounting brackets designed by Cayman BergMorales. 

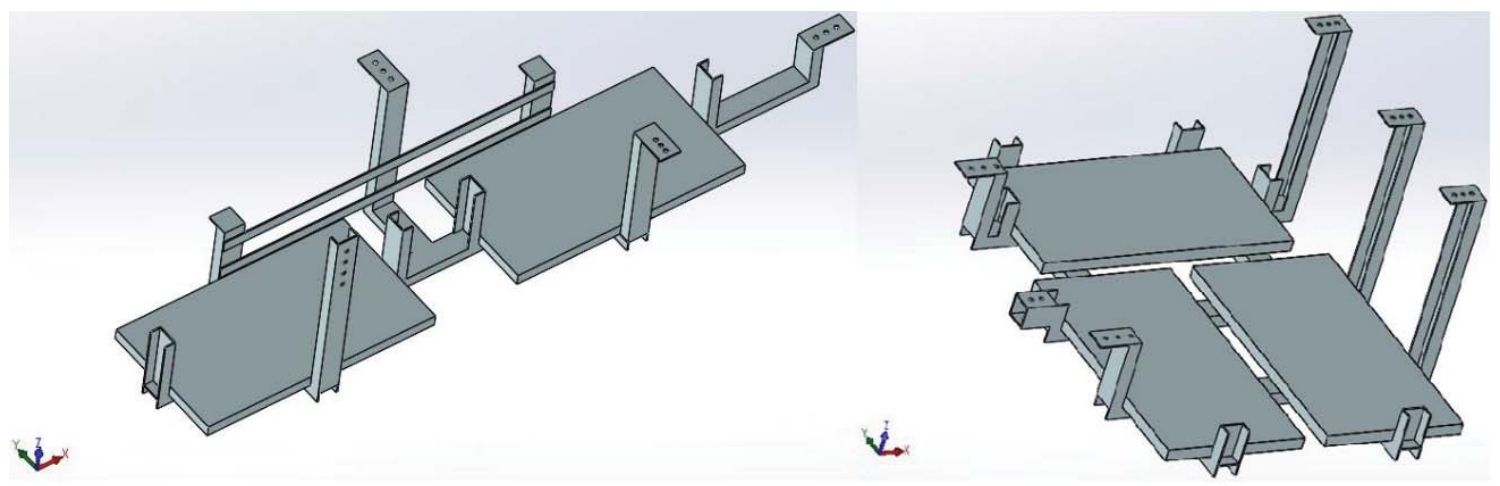

Figure 13. Side and Back bracket design

The third bracket design is not yet drafted. Once these two brackets are finalized, work on the third bracket will start. For the purpose of this report the missing bracket was assumed to be the mirror image of the other side bracket. However it will not be exactly the mirror design since the geometry of the frame is not perfectly symmetric. Figure 14 shows the three brackets assembled on the frame along with the seven tanks.

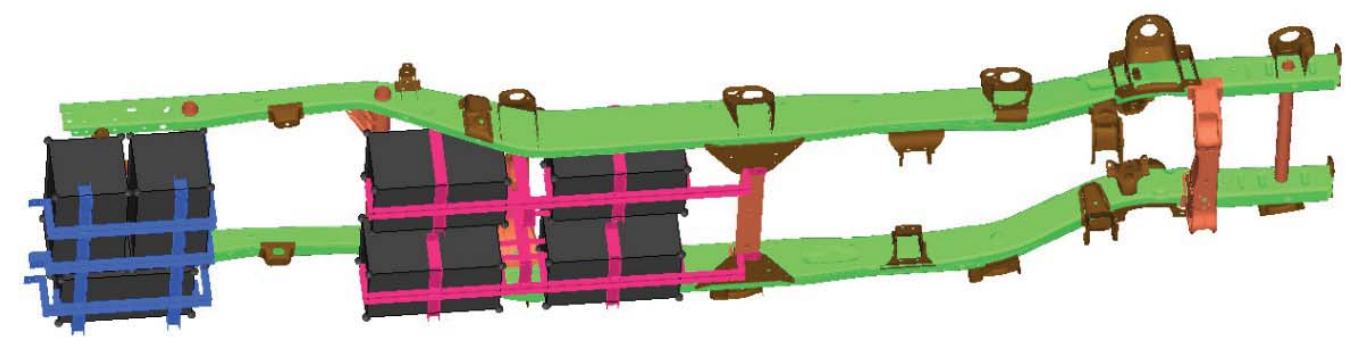

Figure 14. Side and Back brackets mounted on the frame 


\section{Computational Analysis}

\subsection{Geometry cleanup and simplification}

The frame sub-assembly was imported in Hypermesh 12.0 software in *.step format. Before commencing meshing it was essential to cleanup geometry as there were many small features like small parts, unwanted contour lines and structurally unimportant parts. Auto cleanup feature was used for removing extra contours and simplifying the surfaces on all the components. Some members on the frame could be neglected as they were having no effect on the structure when considering simple static case. Structurally unimportant suggests that these members would contain neither any loads nor any constraints rendering them mere mounts on the frame whose inclusion will have negligent effect on the results. Hence these members were isolated and not included in any process of finite element analysis (FEA). Neglecting these members helped limit the complexity of structure and reduced the simulation period. For example in Figure 15 the highlighted member was excluded from the structure because it was transferring no load to the structure except its weight, which is very little when compared to the size of the structure. Also no load was being transferred on the member from other sub-members. 


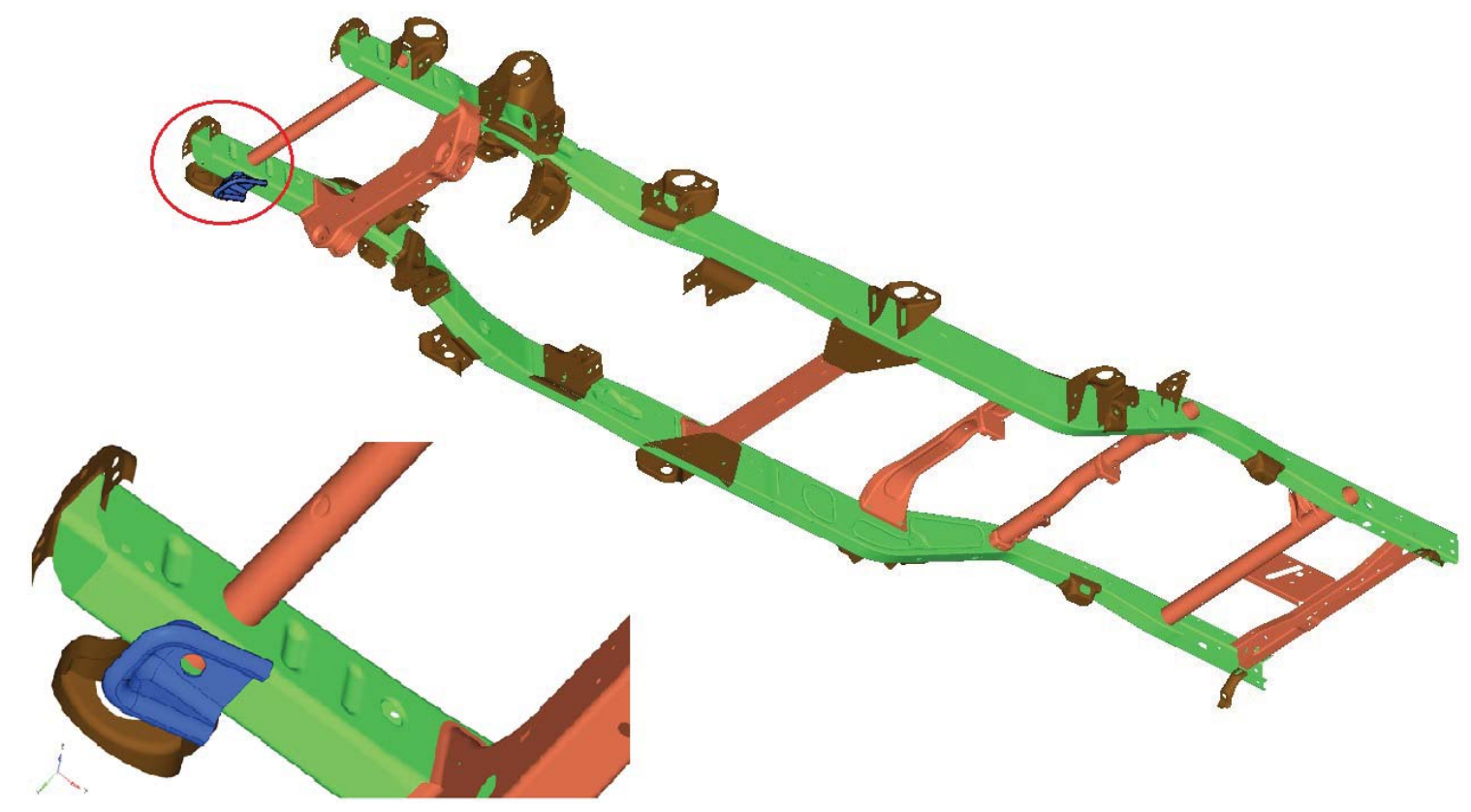

Figure 15. One of components excluded from the analysis

\subsection{Meshing}

The entire frame sub-assembly consists of thin members. All the components in the structure were thin structures. The decision to perform 2D meshing was made due to the thin feature of all the members. The advantage of using 2D meshing is simplification in meshing and less amount of finite elements to process. In thin structures the third dimension is the thickness which is always much less in magnitude than the other two dimensions which form the surface area (Altair University, 2011). For 2D elements this thickness is assigned using the property feature of the software. The other criteria is the surface which is to be selected for meshing. For almost all applications it is beneficial to use the mid-surface of the thin structures as the thickness assigned using property always get split in half on both the sides of the surface (Altair University, 2011). Hypermesh provides an auto-midsurface feature which automatically extracts the mid surface of the 
desired geometry. However the geometry needs to be clean without any discrepancies in the CAD such as uneven thickness or extremely acute angled surfaces. The CAD of the frame was extremely well designed with no problems in the assembly. Hence mid-surfaces of all the sub-components were extracted. In total there were 112 components in the assembly excluding the bolts, nuts, washers and other connectors. Figure 16 shows the mid-surface of a single component

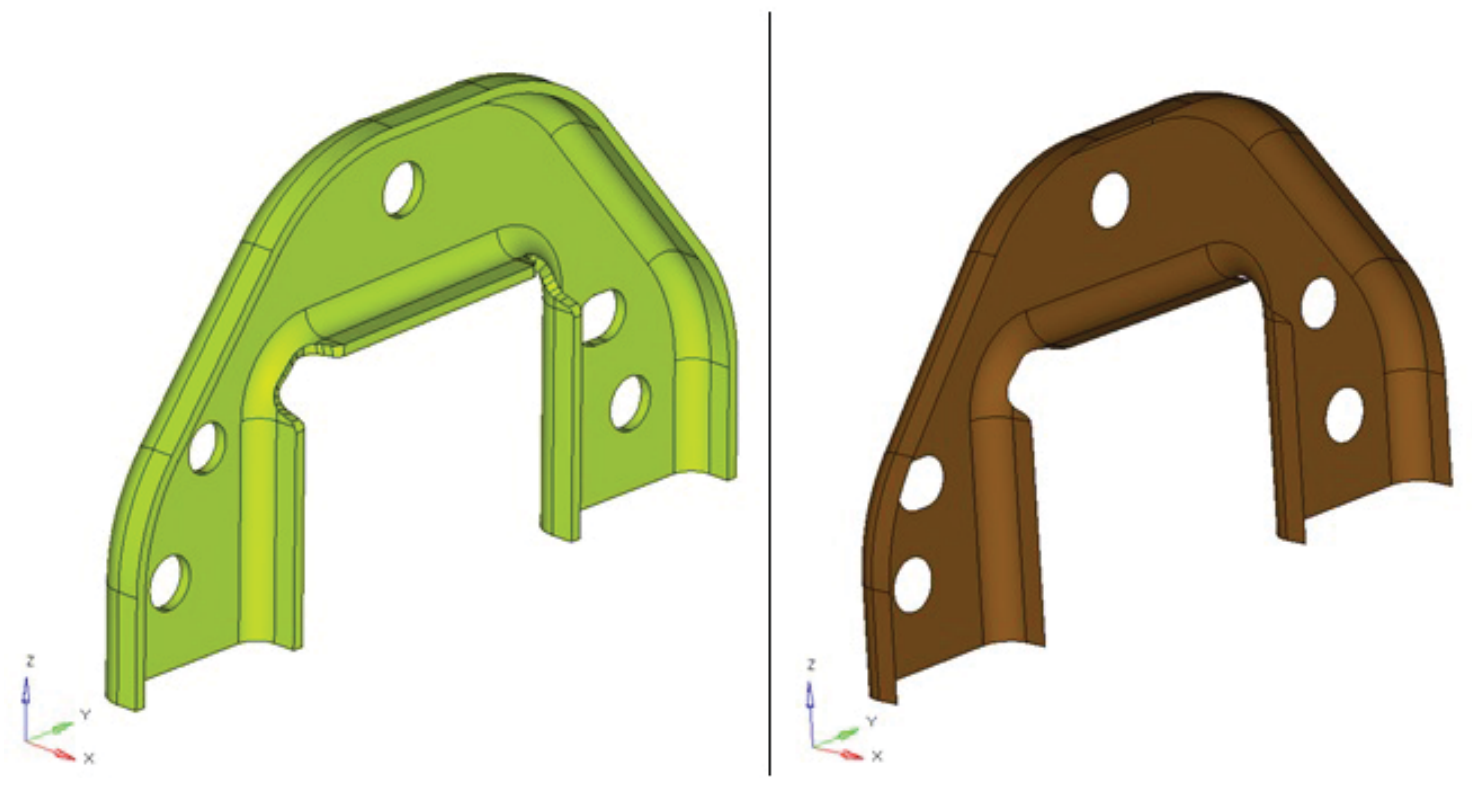

Figure 16. Single component along with its mid-surface

A component in FEA software is an entity which contains the geometric data of any single CAD part, also it is responsible to store all the geometric data that is generated during the setup of FEA. All the extracted mid-surfaces were placed in a single component. Then there were three main group components created, namely the frame side rails, crossmembers and mounting brackets. The mid-surfaces were then divided into these three group components. The side rails component consist of the C-channels that formed the box cross-section frame and were the primary members in the assembly. The cross-member component held all the linking members that connected the two side-rails. The mounting 
brackets component consist of all the mounting brackets were to carry the loads from the vehicle and channel them to the side-rails or cross-members. Figure 17 shows the three group components.

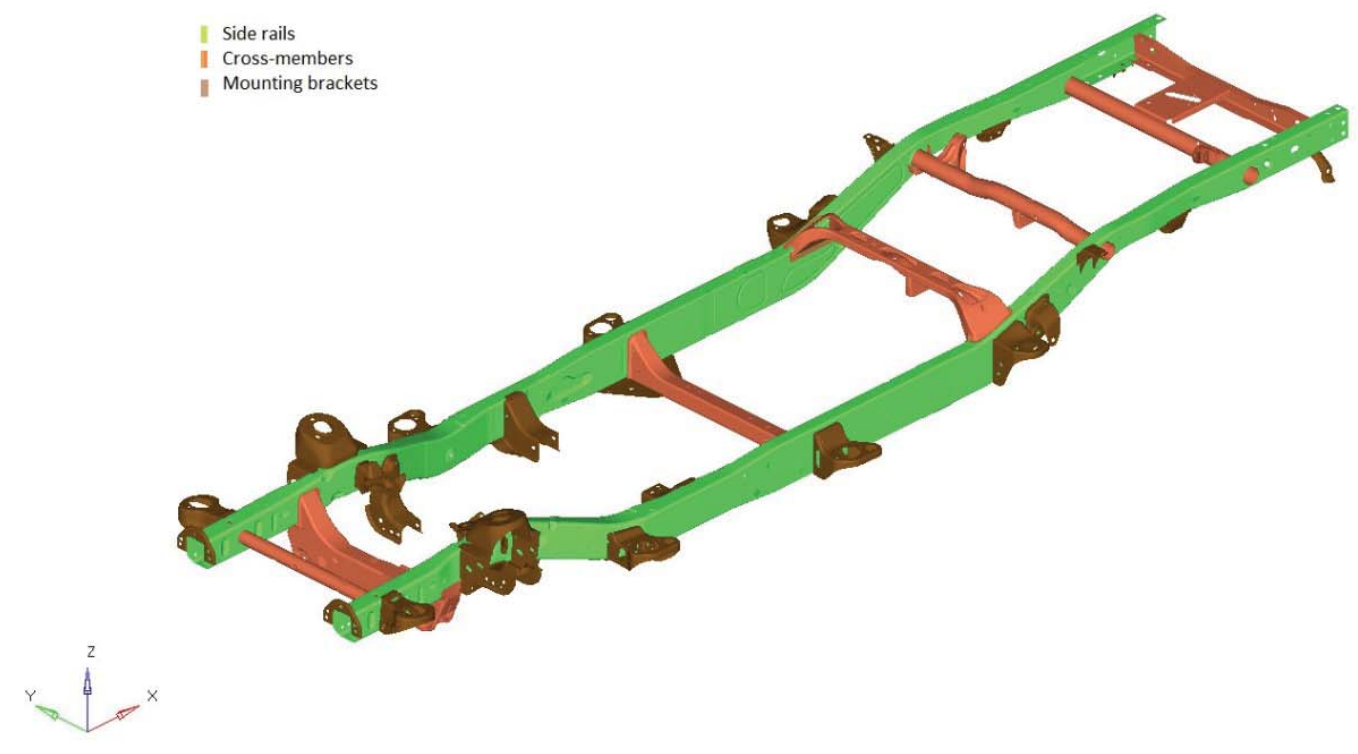

Figure 17. All the components arranged in three main groups

After grouping the components it was convenient to mesh individual parts and then slowly mesh all the parts in the model. As 2D meshing was to be performed, 2D AutoMesh feature was used for meshing the parts. Meshing was done surface by surface using interactive style of meshing. Interactive meshing helps in generating clean, smooth and desired mesh pattern. For 2D type meshing there are two basic element types trias (3 node element or triangles) and quads (4 node element or quadrilaterals). Mesh element type was kept mixed type which is a combination of trias and quads. This type is used when the geometry consists of uneven curves, awkward angles and curved edges. The element size was decided by performing the mesh validation of one single part in the assembly. Mesh validation is a series of analyses on a single part with varying element sizes but fixed 
boundary conditions. The decision to analyze a single part instead of the entire assembly was made as the size of the assembly was large and time required to mesh and analyze will be large. The sizes were varied from as low as 0.01 inches to 1 inches. This range was decided considering the overall size of the part and the smallest dimension it held other than its thickness. Since all the minute details from the CAD were included the element size was needed to be kept as low as 0.01 inches. The data acquired from the analysis is then plotted on a graph where the element sizes are compared with the respective von Mises stress that is generated. The following plot in Figure 18 shows the results of mesh validation along with a linear fitted curve to give the nature of the plot.

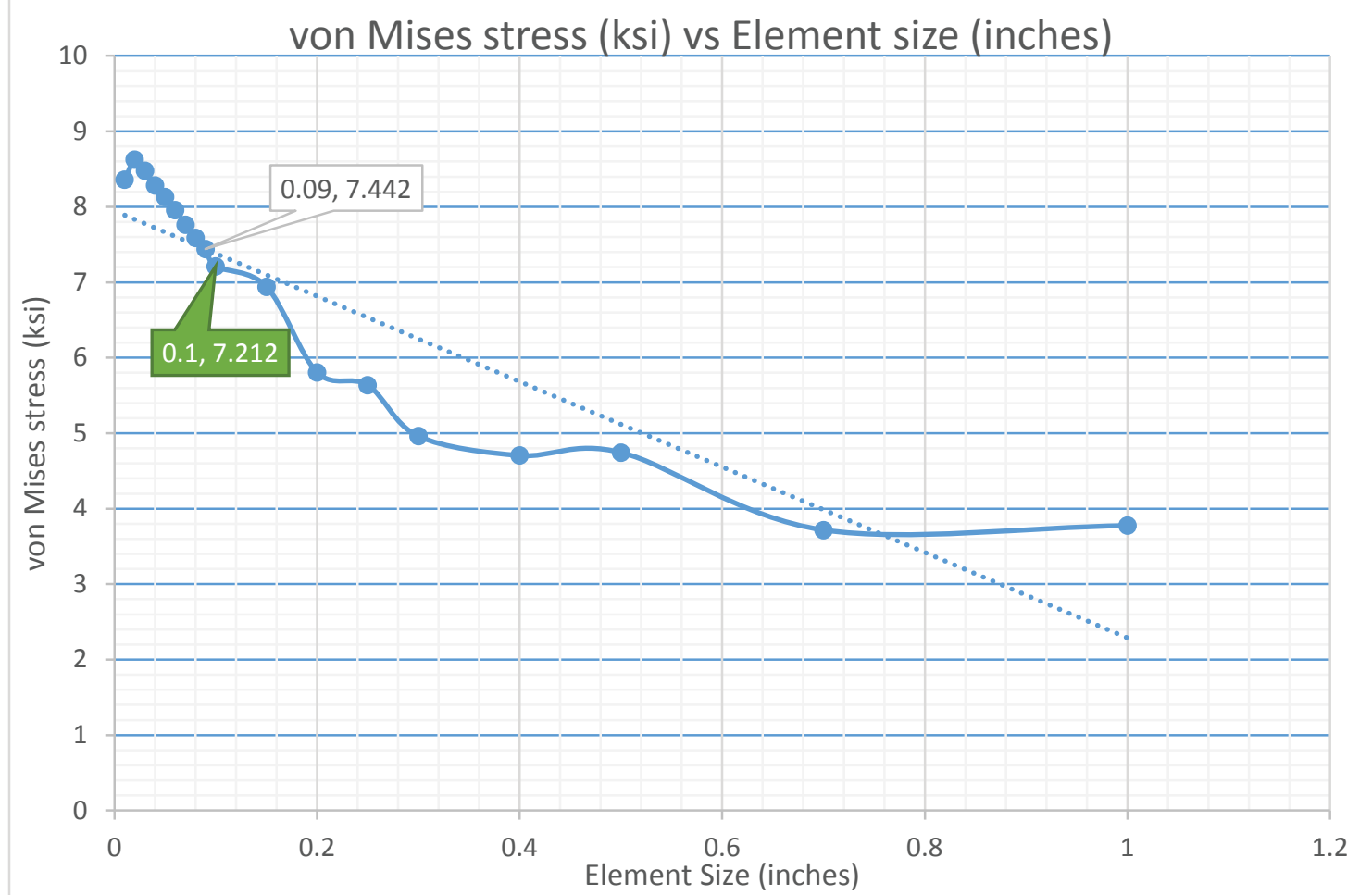

Figure 18. Mesh Validation plot of a single component

From Figure 18 it can be seen that smaller element sizes are required to generate a constant value of maximum von Mises stress. Since the overall structure was large in size 
it would be impossible to mesh the model with element sizes as low as 0.01 inches or less. Hence the size of 0.1 inches was selected as this size provided balance between the finer mesh size and overall structure of the model. The simulation time would also get reduced in case of 0.1 inches element size. Table 1 gives the idea of the simulation time estimate for a single part as well as for the entire assembly. The value of the full model computation time for 0.09 inches element size is an approximated value generated using simple unitary method.

Table 1. Computation time estimate

\begin{tabular}{|r|r|r|r|}
\hline \multicolumn{1}{|c|}{ Sr. } & Element & \multicolumn{2}{|c|}{ Computation time (min) } \\
\cline { 3 - 4 } No. & Size (inches) & Single component & Full model \\
\hline 1 & 0.09 & $8.33 \times 10^{-02}$ & $>94.6389$ \\
\hline 2 & 0.1 & $5.00 \times 10^{-02}$ & 56.78333 \\
\hline
\end{tabular}

All the components in the three groups were meshed using mixed style meshing and 0.1 inches element size. This mesh size will not help generate the maximum possible stress value, but give an estimate of a value very near to the maximum. Figure 19 shows a part of the meshed assembly. 


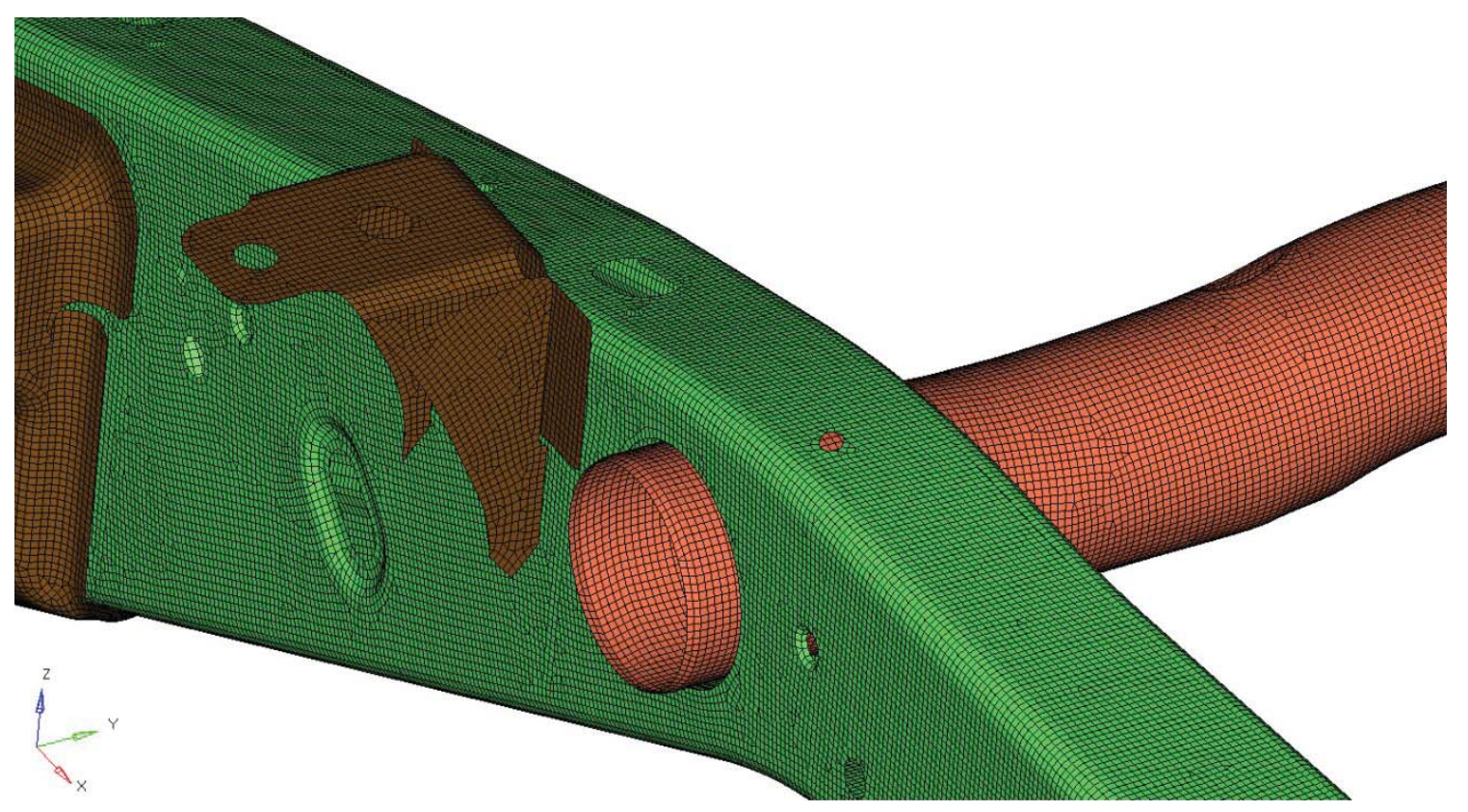

Figure 19. Detailed view of the mesh pattern

Once the meshing was completed, connecting all the meshed parts was performed. Most of the parts in the assembly were welded and some had bolted connections. The bolted connections were removed to simplify the setup. These connections were replicated using direct load applied on the bolt holes, assuming that the bolt did not fail under the load. This assumption makes sense since the analysis was static type analysis and the load applied was that of the vehicle body and maximum payload that the manufacturer rated. Weld connections were made using 1D seam connectors feature. This feature simulates the actual seam welding that is done between two parts. Nodes on the edges of a part to be welded are selected and the two parts to be welded are selected, the type of seam is selected as weld and the connectors are created. All the connectors were separately placed in a different component. Figure 20 shows the connectors that were used. 


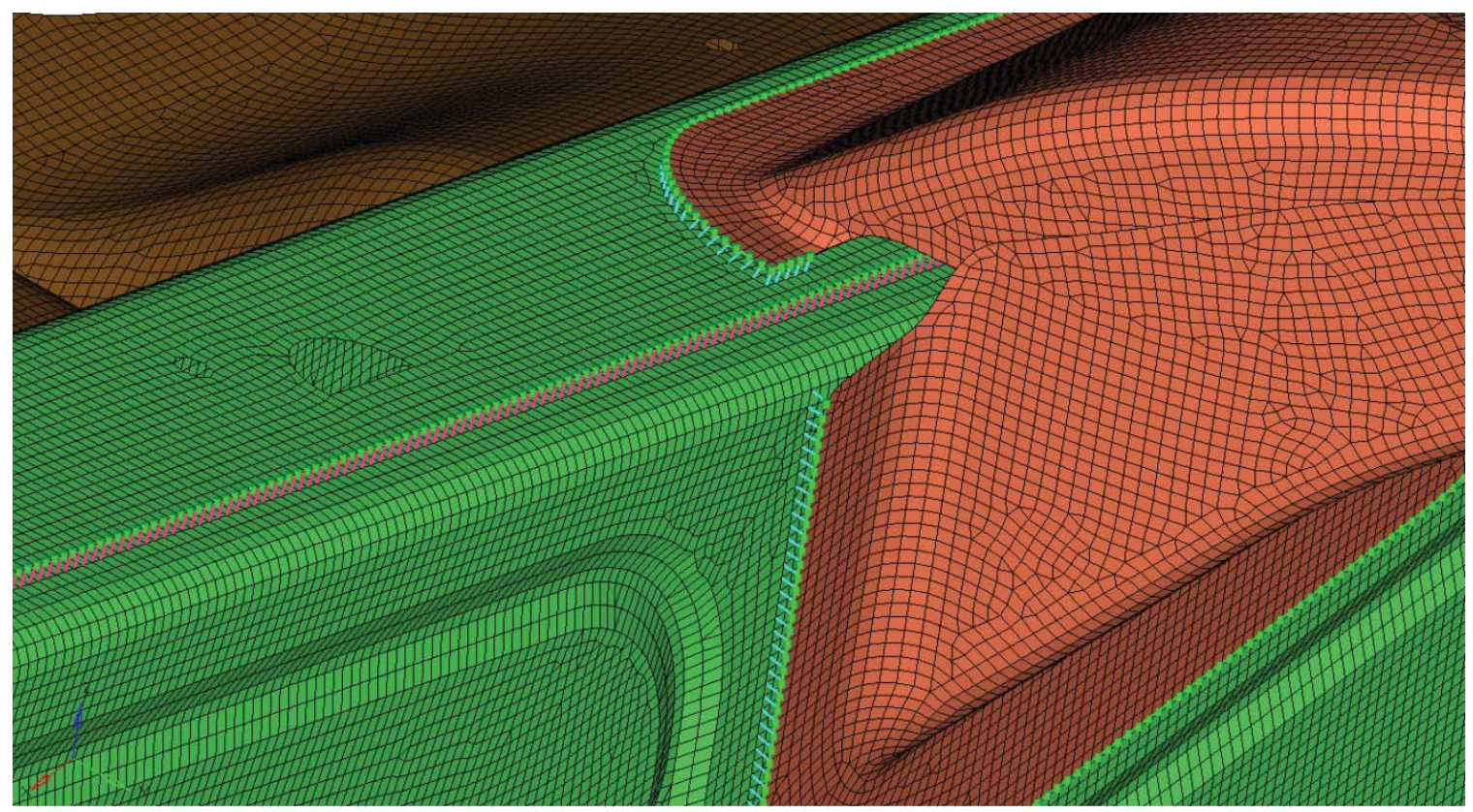

Figure 20. Detailed view of the seam weld connectors used for connecting all the components in the assembly

\subsection{Quality check}

All the elements were passed through the quality index before assignment of material and property. For 2D mesh elements, the primary quality checks include aspect ratio, skewness, and jacobian.

Aspect ratio is the ratio of maximum length edge of an element to the minimum length edge of that element. The value of aspect ratio should not be more than 5 . For the frame assembly the maximum value was 4.93 . Skewness is the parameter which gives the angle of twist for an element. In case of twisting the angle should not exceed 45 degrees. Highest skew recorded was 40 degrees. Jacobian gives the measure of deviation of an existing element with an ideal element of same size and shape. The value should not be less than 0.6. Lowest recorded jacobian was 0.60. (Altair University, 2011)

\subsection{Materials and Property}


2015 Chevrolet Silverado truck comes under third generation of the Silverado series. SAE International published a paper in affiliation with General Motor titled "GM 980X - Potential Applications and review”. This paper was published in 1977 and it discussed the development and applications of a custom high strength low alloy steel. High strength low alloy steels (HSLA) are used for automotive applications as the material for vehicle parts that handle high loads and are light in weight (General Motors, 2013). SAE HSLA steels follow a standard nomenclature. The first numeral represents the group of steels, for example digit 9 represents high strength low alloy steels. The second and third digits indicate the minimum yield strength of the material in kilo pounds per square inch (ksi) and the letter $\mathrm{X}$ indicates that the steel contains niobium, vanadium, nitrogen and other elements used in the alloy (Totten, 2006). GM 980X is similar to SAE 980X, however it has lower yield strength and high work hardening rate. Due to the high work hardening the distribution of strain is uniform and hence the flow of stresses is more refined (Rashid, 1977). This property suits well for automotive applications as automotive parts, like the frame, are subjected to constant high amount of loads. Following table gives the typical mechanical properties of GM 980X

Table 2. Material Properties of GM 980X HSLA steel (Rashid, 1977)

\begin{tabular}{|c|c|r|r|}
\hline Sr. No. & Property & \multicolumn{1}{|c|}{ English } & Metric \\
\hline 1 & Yield Strength & $55 \mathrm{ksi}$ & $380 \mathrm{MPa}$ \\
\hline 2 & Tensile Strength & $95 \mathrm{ksi}$ & $650 \mathrm{MPa}$ \\
\hline 3 & Elastic Modulus & $29900 \mathrm{ksi}$ & $206 \mathrm{GPa}$ \\
\hline 4 & Poisson's Ratio & 0.29 & 0.29 \\
\hline 5 & Density & $0.28 \mathrm{lbs} . / \mathrm{in}^{3}$ & $7.75 \mathrm{~g} / \mathrm{cc}$ \\
\hline
\end{tabular}


An isotropic material was created in Hypermesh and the properties listed in Table 2 were assigned. In every FEA software a material is accompanied by a property. Property helps define the mesh that is being used. For example in a 2D mesh it is essential decide its third dimension or in a $1 \mathrm{D}$ mesh it is essential to define its cross-section. Hence a property of type PSHELL was created. This is the commonly used property for a 2D mesh in Hypermesh. Depending on the thicknesses of all the parts individual properties were created. Total 21 properties with different thickness values were created. Figure 21 shows the thickness generated in a single component in the model due property assignment.

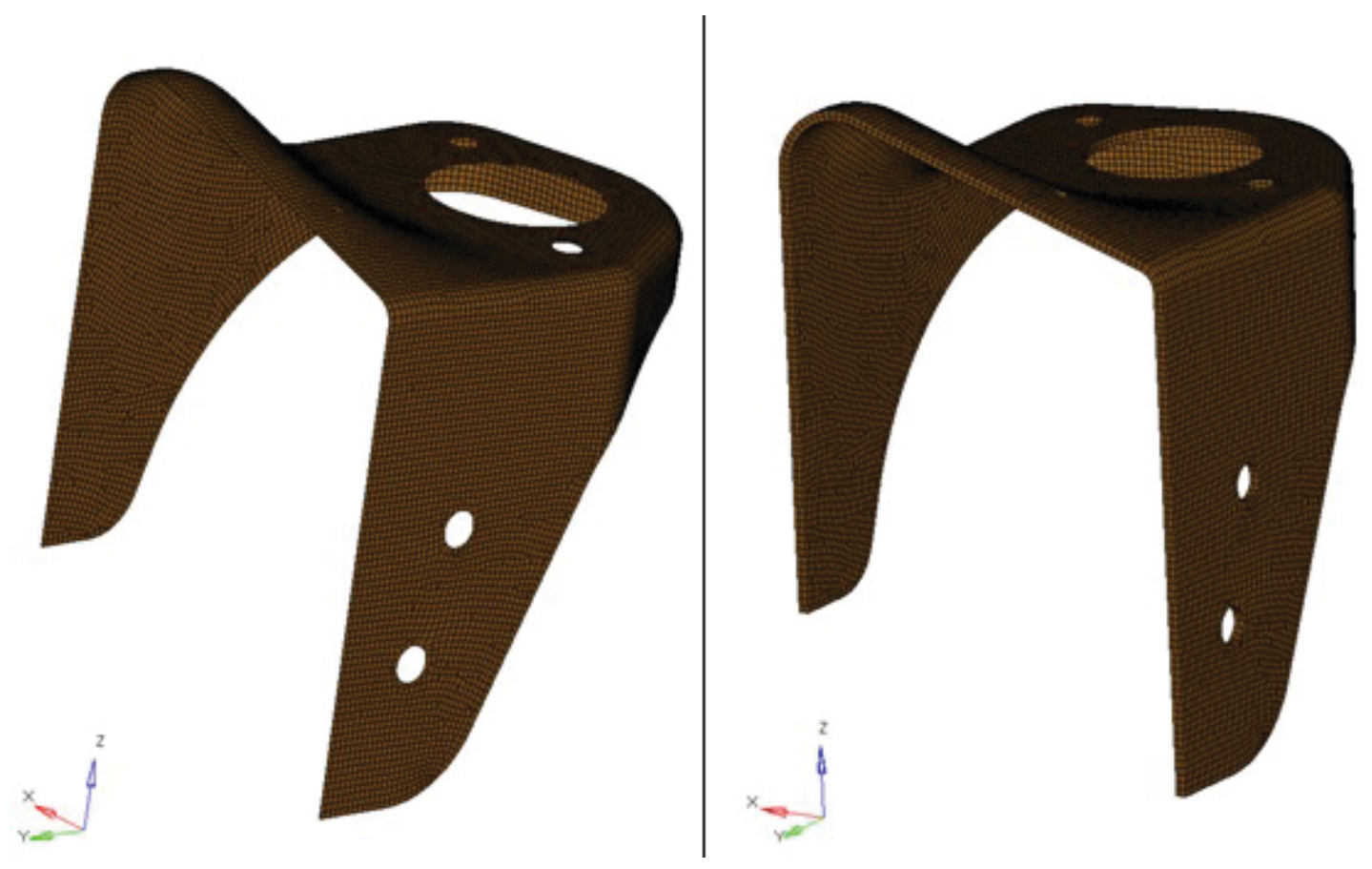

Figure 21. Thickness assigned to the component using PSHELL property

\subsection{Load estimation for static analysis}

The primary weight on a pickup truck frame is exerted by the vehicle body, engine, power-train, passengers and cargo. As mentioned in the 2015 Chevrolet Silverado 1500 catalog, the following details were extracted. (General Motors, 2015) 
Maximum Gross Vehicle Weight Rating $($ GVWR $)=7600 \mathrm{lbs}$

$$
\text { Maximum Payload }=1850 \text { lbs, }
$$

where the gross vehicle weight rating is the maximum weight of the vehicle, which includes weight of the body, chassis, engine, transmission, accessories, passengers, cargo, and fluids which includes lubricants and fuel. The mass of the chassis was determined using Solidworks software, and amounts to little less than 480 lbs. Hence the weight on the frame can be calculated by subtracting the chassis weight from the GVWR.

$$
\text { Load on vehicle frame }=7600-480=7120 \mathrm{lbs}
$$

Since the liquid fuel tank is excluded from the model, the weight of the liquid fuel and the fuel tank should also be removed from the total load on the frame. However, for the initial analysis we will include the weight of the tank and fuel, as the purpose of this study will also be to see the stress plot with original frame configuration. The front-to-rear percentage weight distribution for the 2015 Silverado is 59/41. This ratio is for the empty truck without any passenger and cargo load. We will assume that this ratio is maintained under full load. Hence the total load was divided into two parts: the load on the front portion and on the rear portion of the vehicle.

$$
\begin{aligned}
& \text { Load on Front portion of frame }=0.59 \times 7120=4200.8 \mathrm{lbs} \\
& \text { Load on Rear portion of frame }=0.41 \times 7120=2919.2 \mathrm{lbs}
\end{aligned}
$$

With the vehicle CAD as the reference, all the locations on the frame which supported the body, engine, transmission, and cargo were noted. Figure 22 shows the points on the frame 
where the load is distributed. Total 26 locations were noted, 18 in the front section and 8 in the rear.

$$
\begin{aligned}
& \text { Load on each location in the front section }=\frac{4200.8}{18}=233.3778 \mathrm{lbs} \\
& \text { Load on each location in the rear section }=\frac{2919.2}{8}=364.9 \mathrm{lbs}
\end{aligned}
$$

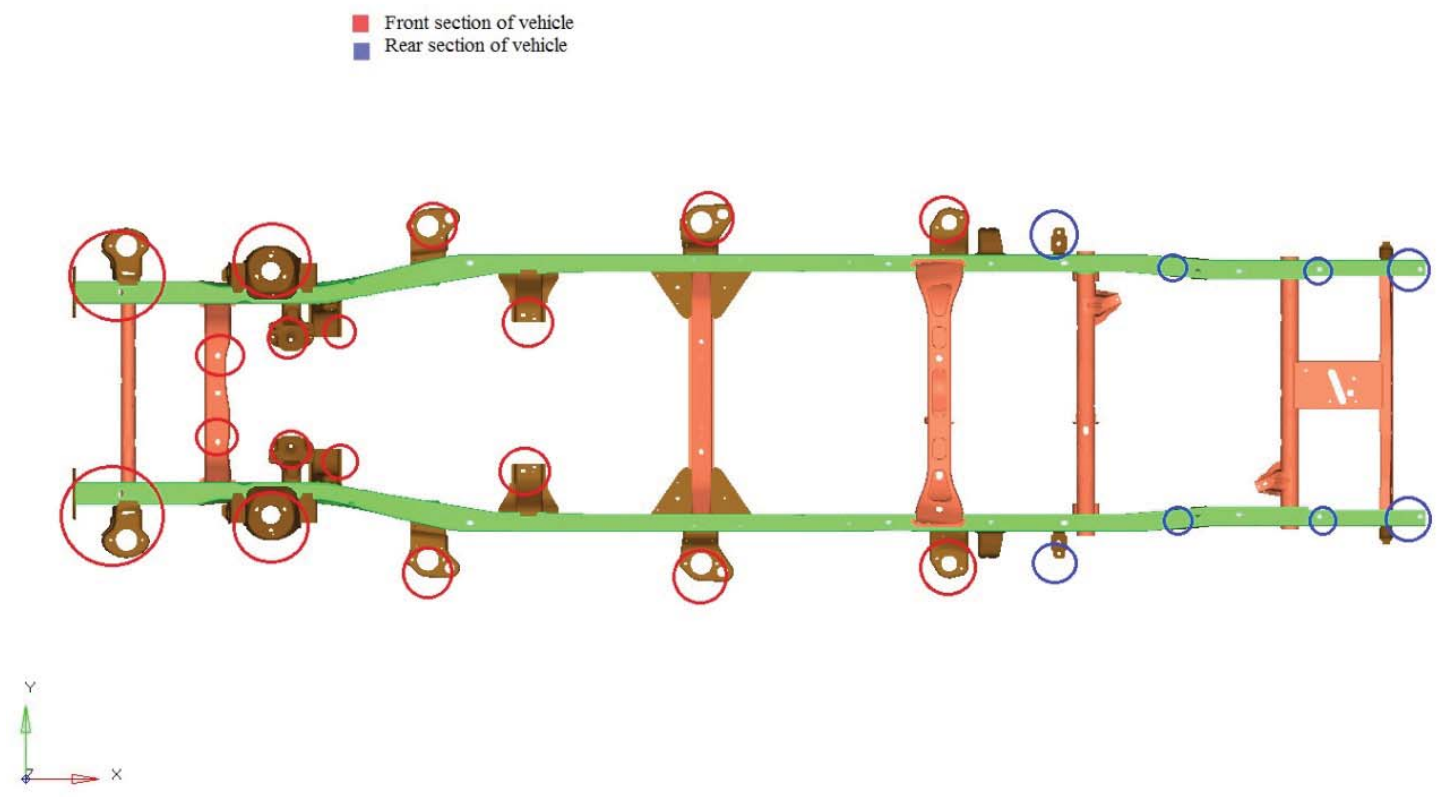

Figure 22. Locations where the total load is distributed

\subsection{Forces and Constraints}

Once the total load on the frame was estimated, a load collector was created in Hypermesh. The calculated load for each location on the frame was assigned as a uniformly distributed load on the selected locations using rigid elements. Rigid elements are pseudoelements which are not part of the structure and do not absorb or exert energy on their own, they merely transfer energy from one node to another. Another load collector was created for applying the constraints to the model. From Figure 23, for the front section, the 
locations 1 and 3 show where the control arms connect the wheel to the frame. The connecting points in location 1 were totally fixed in all degrees of freedom, both translational and rotational. The connecting points in location 3 were totally fixed in $\mathrm{X}$ and $\mathrm{Z}$ directions since relative motion in axial direction $\mathrm{Y}$ is a possibility. For the rear section, the locations 2 and 4 showing the location of mountings which were connected to the leaf springs and the shock absorbers which limit the displacement of the rear wheel shaft were fixed. The connecting points in location 2 and 4 were totally fixed in $\mathrm{Z}$ direction only, since relative motion in directions $\mathrm{X}$ and $\mathrm{Y}$ is a possibility. Figure 24 shows the free body diagram of a single side rail considering the frame is perfectly symmetric. Figure 25 shows the $3 \mathrm{D}$ view of the detailed loading of the frame with the arrows showing the location of loads and constraints.

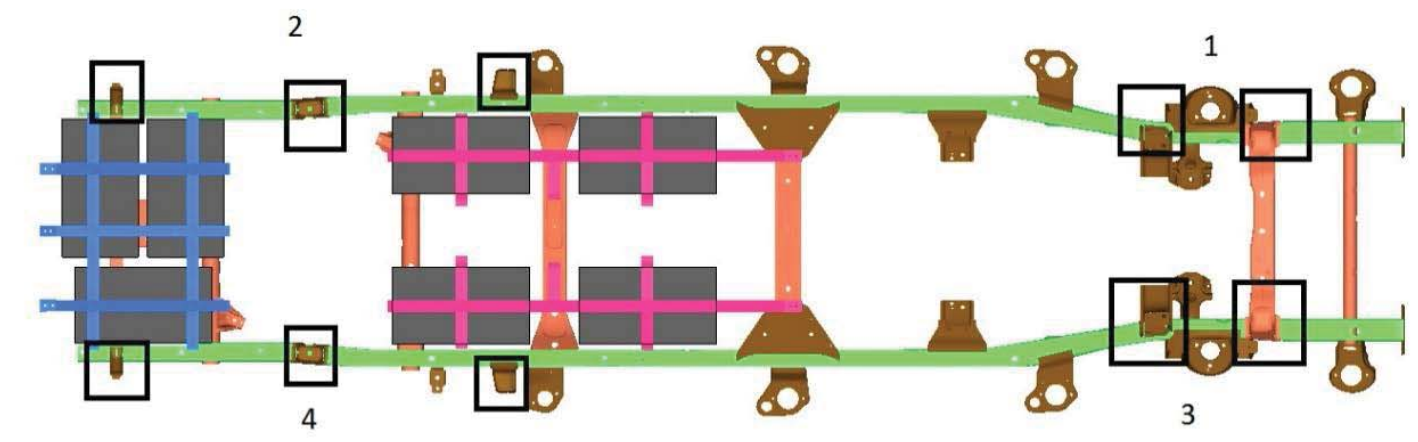

Figure 23. Bottom view of the frame indicating the location of constraints 


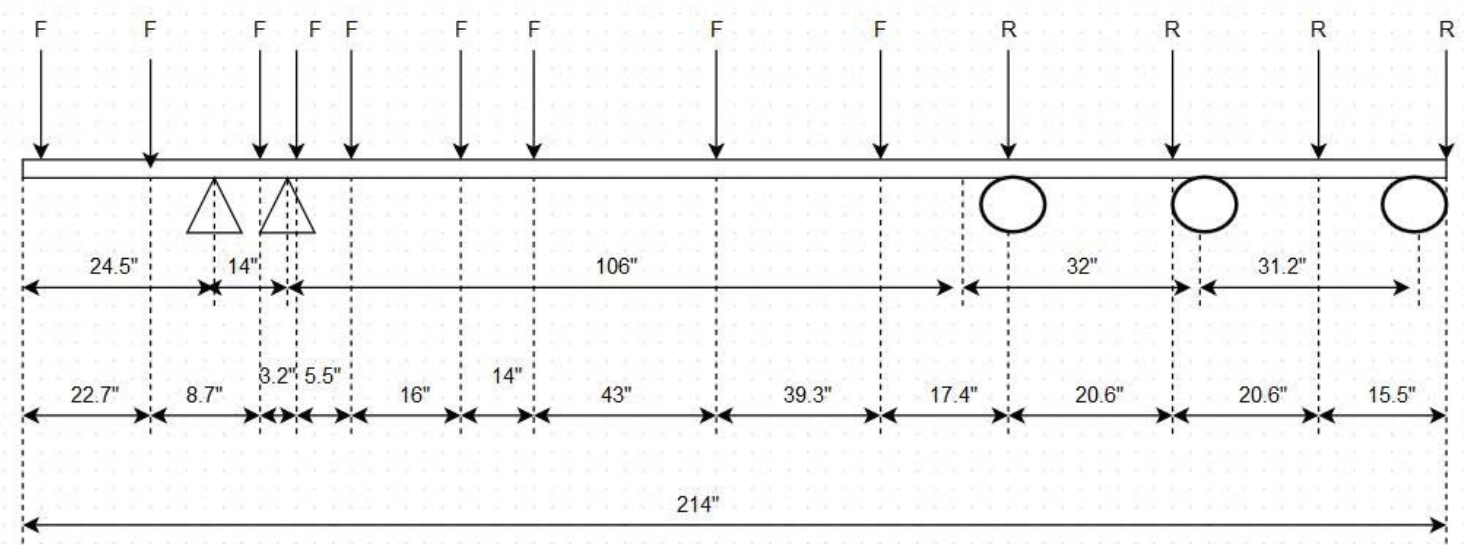

$\mathrm{F}=233.3778 \mathrm{lbs} .=$ Load on each front section locations

$\mathrm{R}=364.9 \mathrm{lbs}$. $=$ Load on each rear section locations

Figure 24. Free body diagram of a single side rail of the symmetric frame

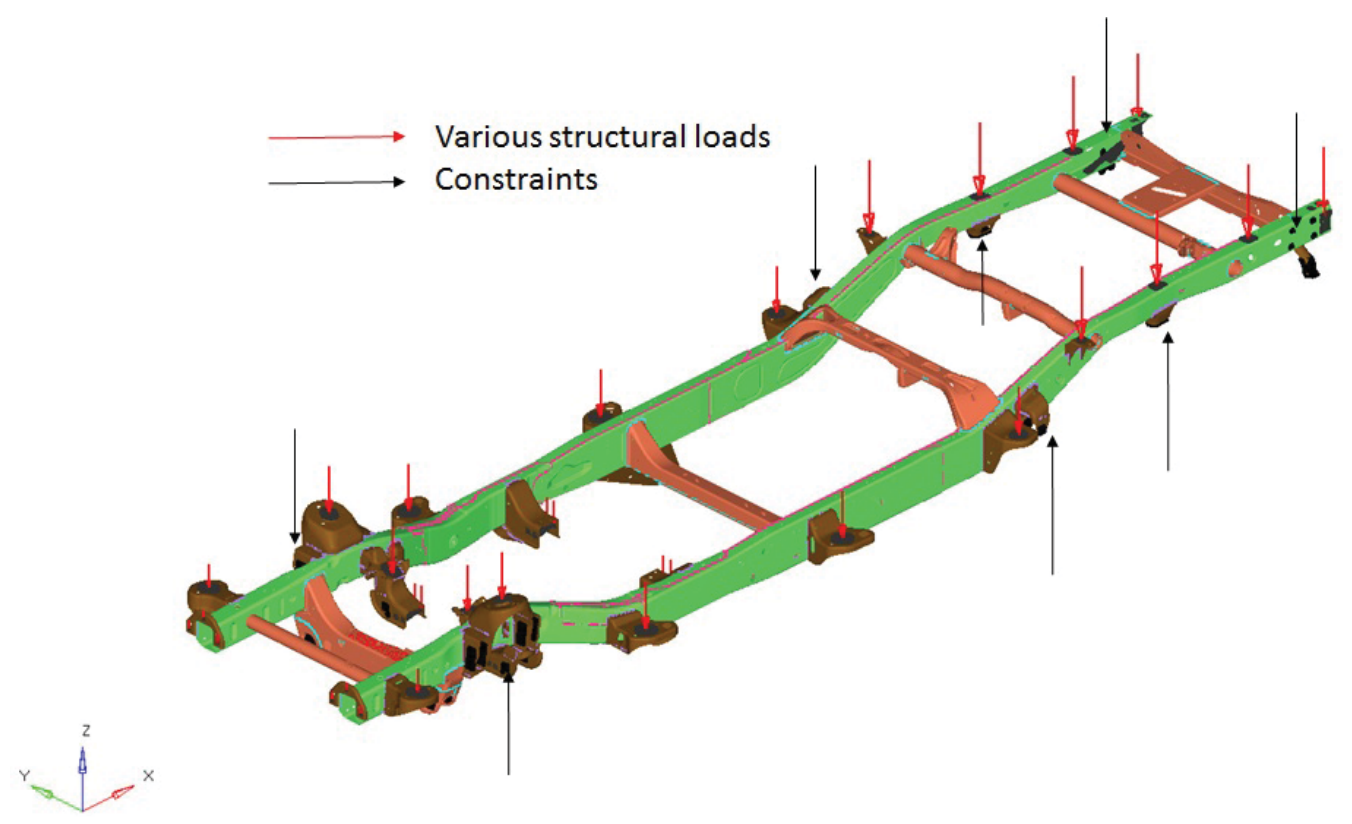

Figure 25. Layout of the frame with boundary conditions

After all the loads were created, a load step was set up in order to simulate the static analysis. The load step is used to define the role of the load collectors and extract the desired output depending on the analyst's input. The input entities were the loads and constraints applied according to sections 3.5 and 3.6. For this simulation the element 
stresses for 2D elements and displacement output were extracted under a simple static subcase.

\subsection{Inclusion of brackets and non-cylindrical tanks}

The initial simulation did not include the new brackets or the weight of the rectangular tanks that are to be mounted. The purpose of this analysis was to generate the stress plot and get access to the locations where the new brackets with the seven tanks could be mounted. The second simulation was run with the inclusion of these two components. The CAD of the two brackets, side bracket and back bracket, was imported in the current model file. As they were individually imported, they were not assembled to the frame. Hence, the brackets were first positioned on the frame and then, connectors were used to attach them to the frame. In reality the brackets are to be bolted on the frame, but due to the absence of the bolt holes in the CAD, they were connected using a spot weld type connector. This assumption would prove wrong if there was any stress generation near the connection. The third side bracket was created using the existing side bracket. As the brackets were simple C-channels, 2D meshing was done with extraction of mid-surface and thickness assignment using PSHELL property. Figure 26 shows the three brackets assembled on the frame. The material of the C-channels was A36 mild steel. Table 3 shows the typical mechanical properties of the A36 steel. 


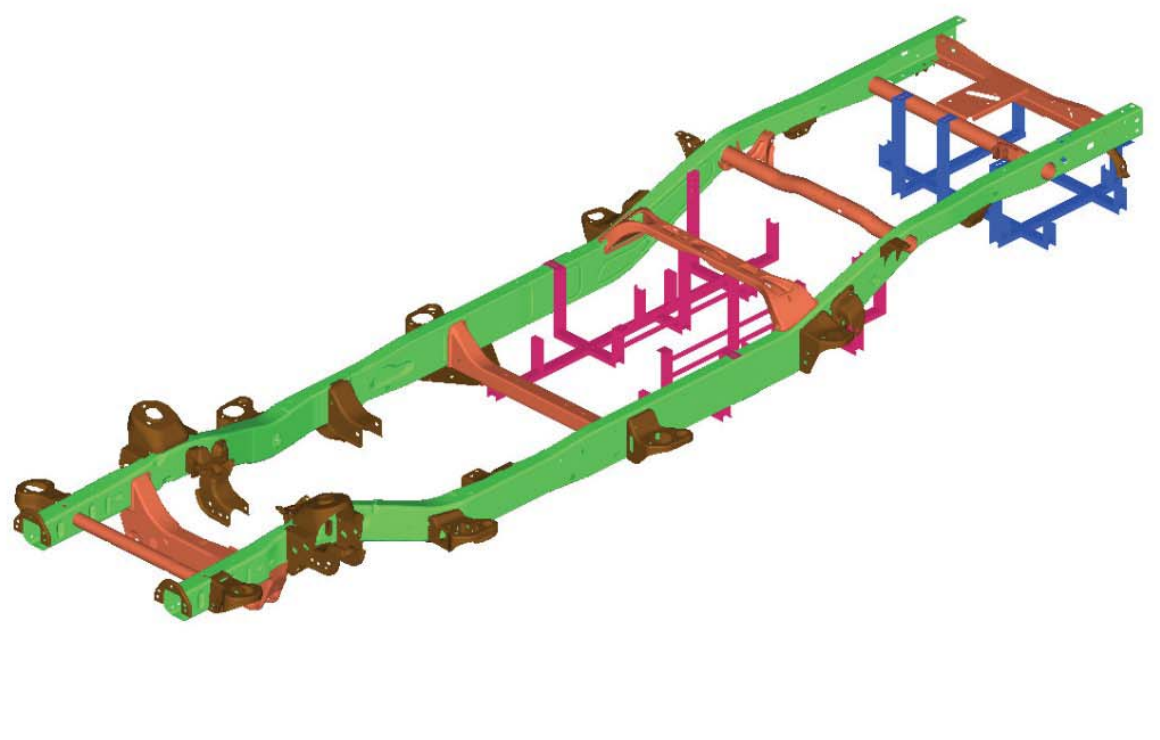

Figure 26. All the three brackets assembled on the frame using spot welds

Table 3. Material properties of A36 mild steel (Matweb, LLC, 2015)

\begin{tabular}{|c|c|r|r|}
\hline Sr. No. & Property & \multicolumn{1}{|c|}{ English } & Metric \\
\hline 1 & Yield Strength & $36.3 \mathrm{ksi}$ & $250 \mathrm{MPa}$ \\
\hline 2 & Tensile Strength & $58 \mathrm{ksi}-79.8 \mathrm{ksi}$ & $400 \mathrm{MPa}$ \\
\hline 3 & Elastic Modulus & $29000 \mathrm{ksi}$ & $200 \mathrm{GPa}$ \\
\hline 4 & Poisson's Ratio & 0.26 & 0.26 \\
\hline 5 & Density & $0.284 \mathrm{lbs} . / \mathrm{in}^{3}$ & $7.85 \mathrm{~g} / \mathrm{cc}$ \\
\hline
\end{tabular}

After meshing the components, these brackets were loaded by simulating the weight of the seven tanks. Rated weight of the empty tanks is 89 lbs. In case of a full tank, the CNG exerts no more than $10 \mathrm{lbs}$. due to its gaseous state. Hence, a total of $700 \mathrm{lbs}$. was uniformly distributed on the brackets, where each full tank weighed 100 lbs. The constraints were kept identical to the previous simulation. Figure 27 shows the weight distribution of the tanks on the brackets. 


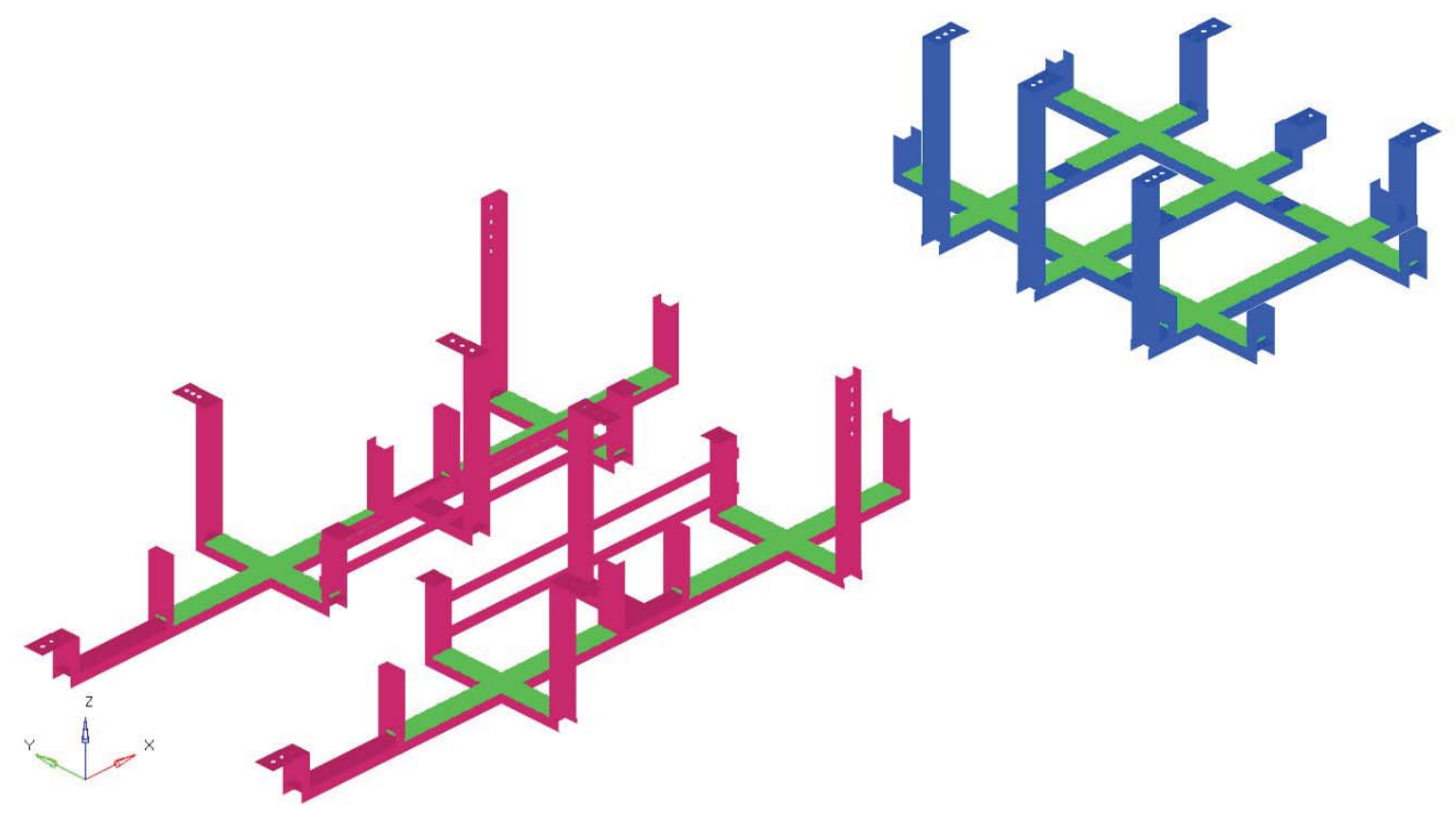

Figure 27. Location of weight distribution on the three brackets

The capacity of the liquid fuel tank in the 2015 Silverado is 26 gal, which is equivalent to 167.075 lbs. In the previous simulation, this weight was included in the total load, but for this case we need to remove this weight, as we are replacing the liquid tank. Assuming the weight of tank to be less than 10 lbs., as it is a thin sheet metal tank, a total weight of 175 lbs. was subtracted from the total load. Also, since the spare tire was removed, additional weight of approximately 40 lbs. of a 22 inch wheel is subtracted from the total load on the rear section of the frame. Here we will assume that the new exhaust assembly is equal in weight with that of the old one. It is noteworthy that the back bracket was designed to be connected partially to the frame and partially to the body, specifically to the trailer hitch receiver. As the body was excluded from the scope of analysis, the connection to the trailer hitch receiver was simulated by using rigids. Rigids were used to link the mounting ports on the bracket to the frame where the body is mounted. This 
approximation is bound to generate some errors, as the connection should not be rigid, but rather elastic.

\subsection{Results}

The analysis was conducted using the Optistruct software. The stress plots and displacement plots were used to study the behavior of the frame. The von Mises stress was used as the parameter to predict whether the structure was strong enough to handle the estimated loads. As the materials used for the entire structure are ductile materials, the von Mises yield criterion is used to predict failure (Roesler, Harders, \& Baeker, 2007). In all the plots, the red color shows the maximum value of the selected parameter, and the blue color shows the minimum value. All the colors in between show intermediate values. The red-colored zones are of particular importance, since they indicate failure of the structure.

\subsubsection{Tanks excluded}

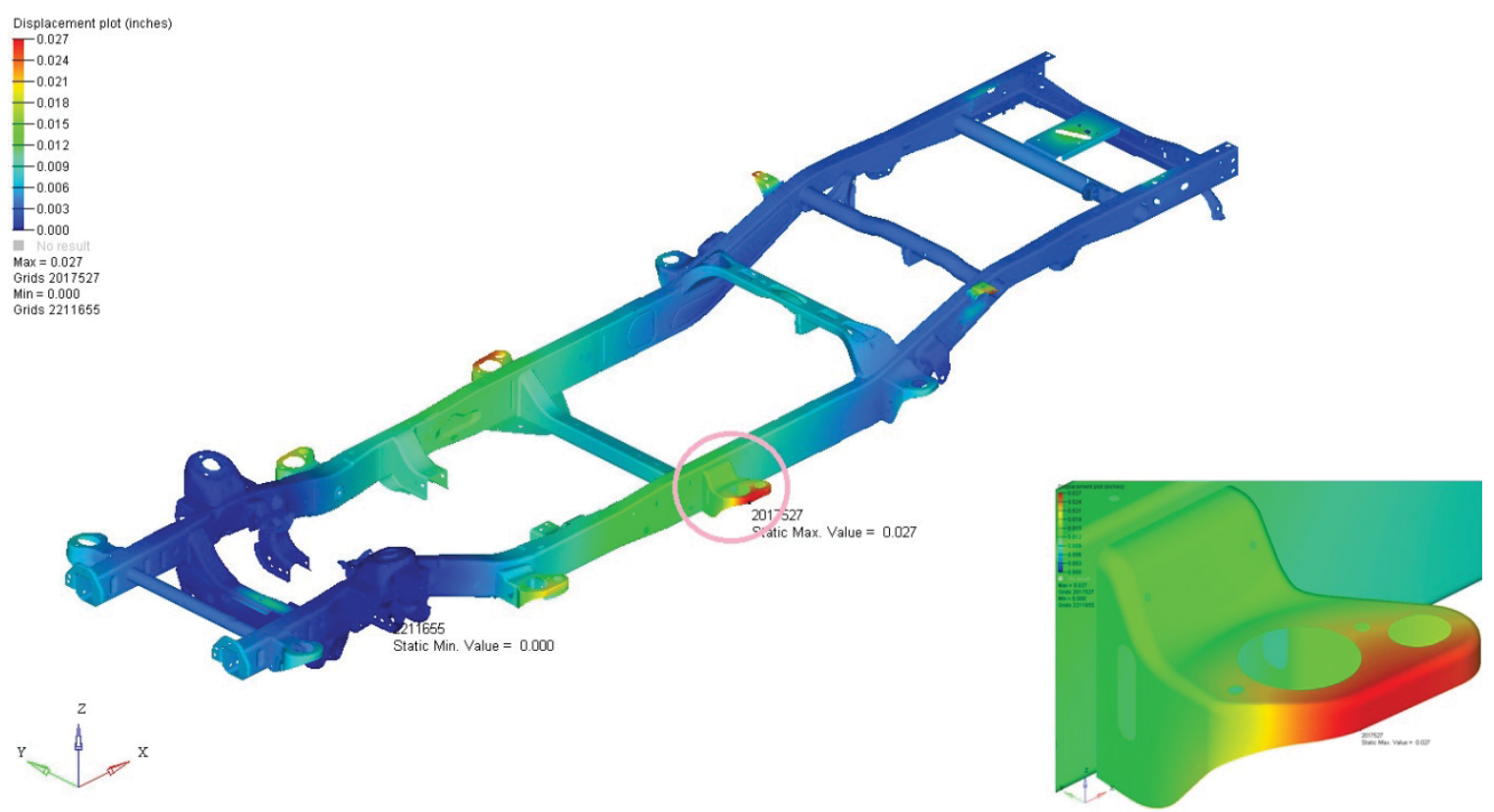

Figure 28. Displacement (inch) plot for the original configuration of the frame 
Figure 28 shows the displacement plot of the frame with the original configuration. The deflection generated was very small considering the size of the model. The value of maximum displacement is 0.027 inch. The component with maximum displacement is an overhanging member highlighted in Figure 28.

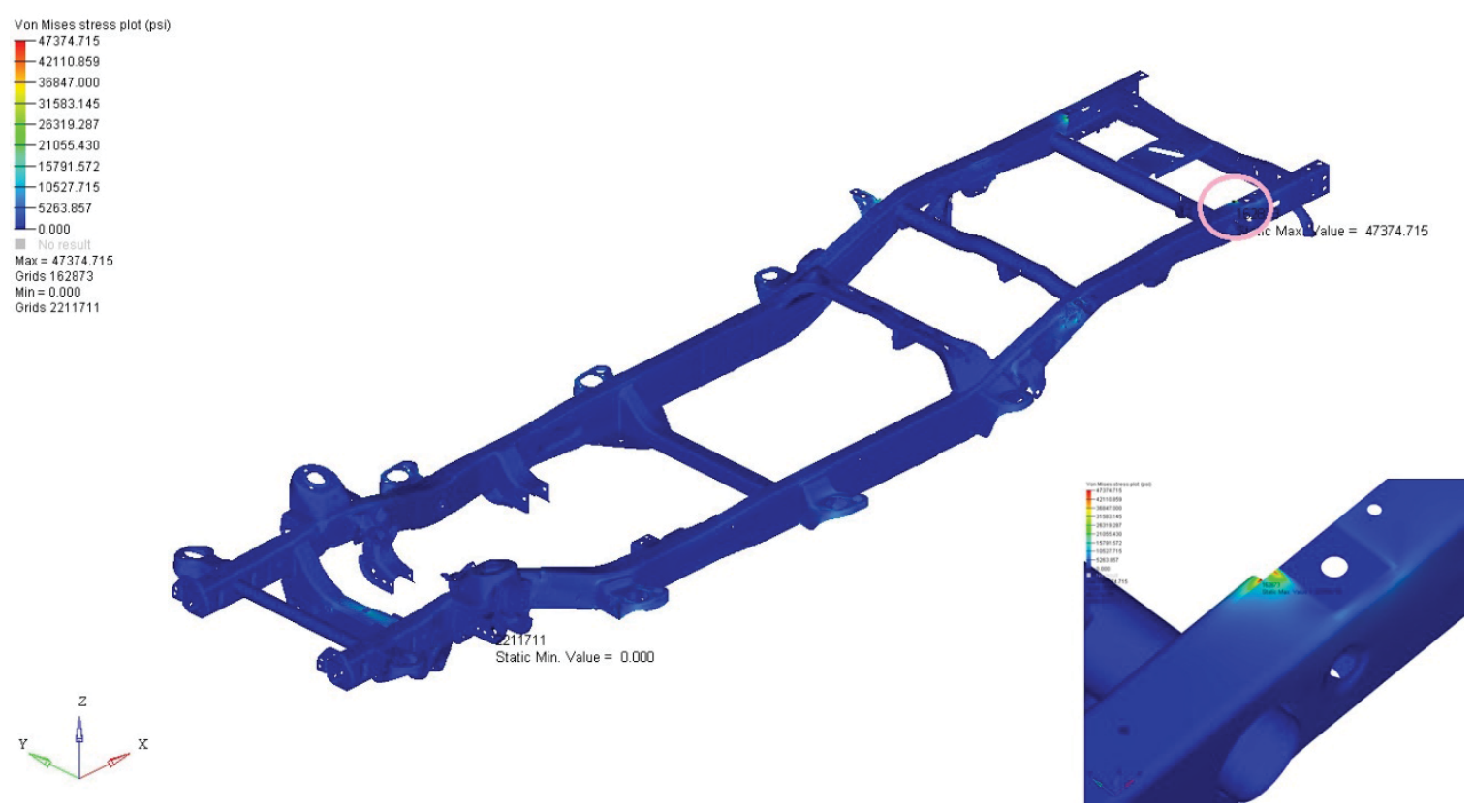

Figure 29. Von Mises stress (psi) plot for the original configuration of the frame

Figure 29 shows the von Mises stress plot of the frame with original configuration.

The maximum von Mises stress recorded was $47.37 \mathrm{ksi}$. The yield strength of the HSLA steel used is $55 \mathrm{ksi}$, hence generating 1.161 factor of safety. The region of maximum stress is an overhanging member, which is bending over the support member, as shown in Figure 27. 


\subsubsection{Tanks included}
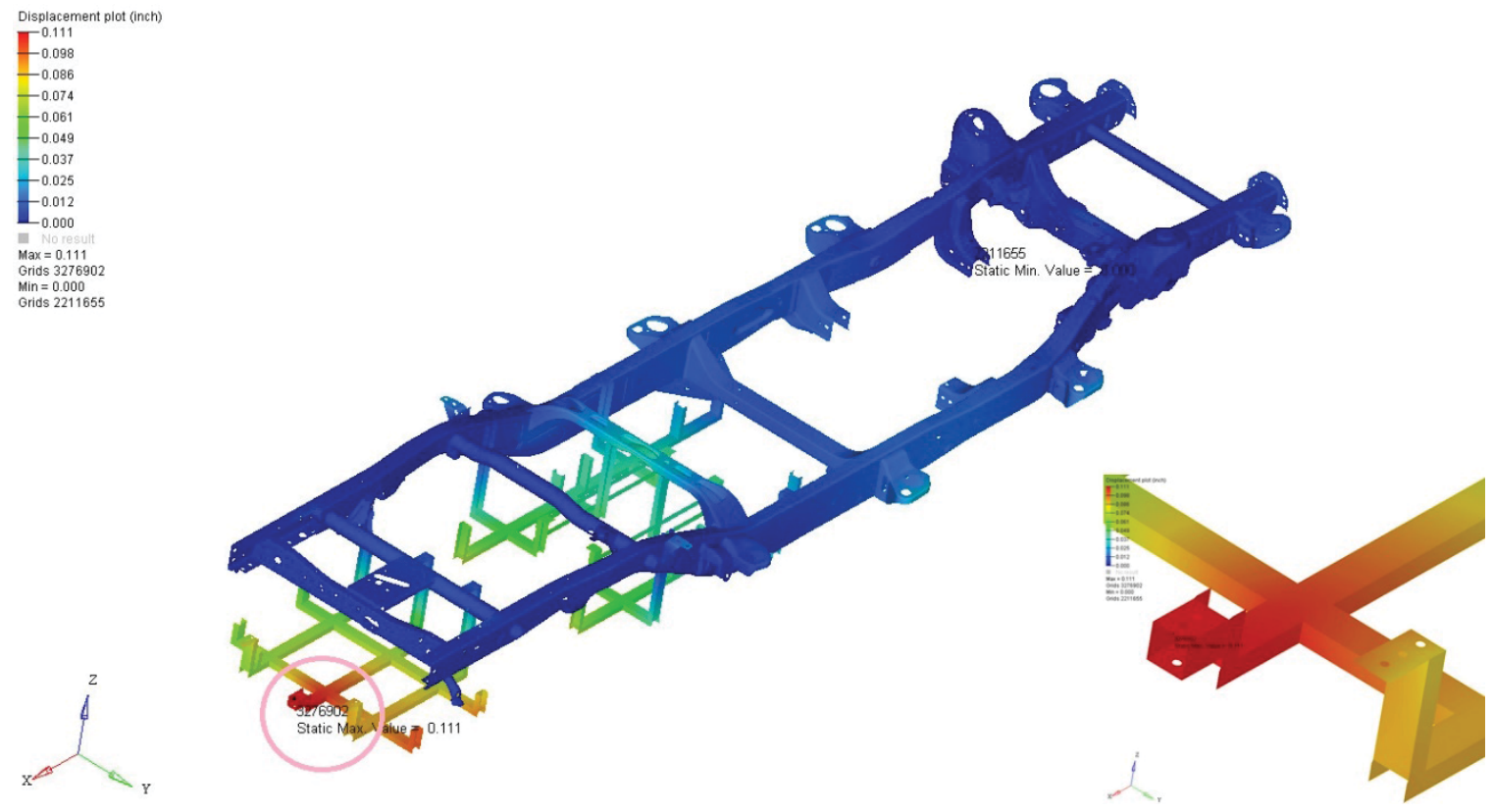

Figure 30. Displacement (inch) plot of the frame with modified configuration

Figure 30 shows the displacement plot of the frame with modified configuration. The value of maximum displacement is 0.111 inches. Most of the deflection occurs in the back brackets, specifically in the member which is to be connected to the trailer hitch receiver. 


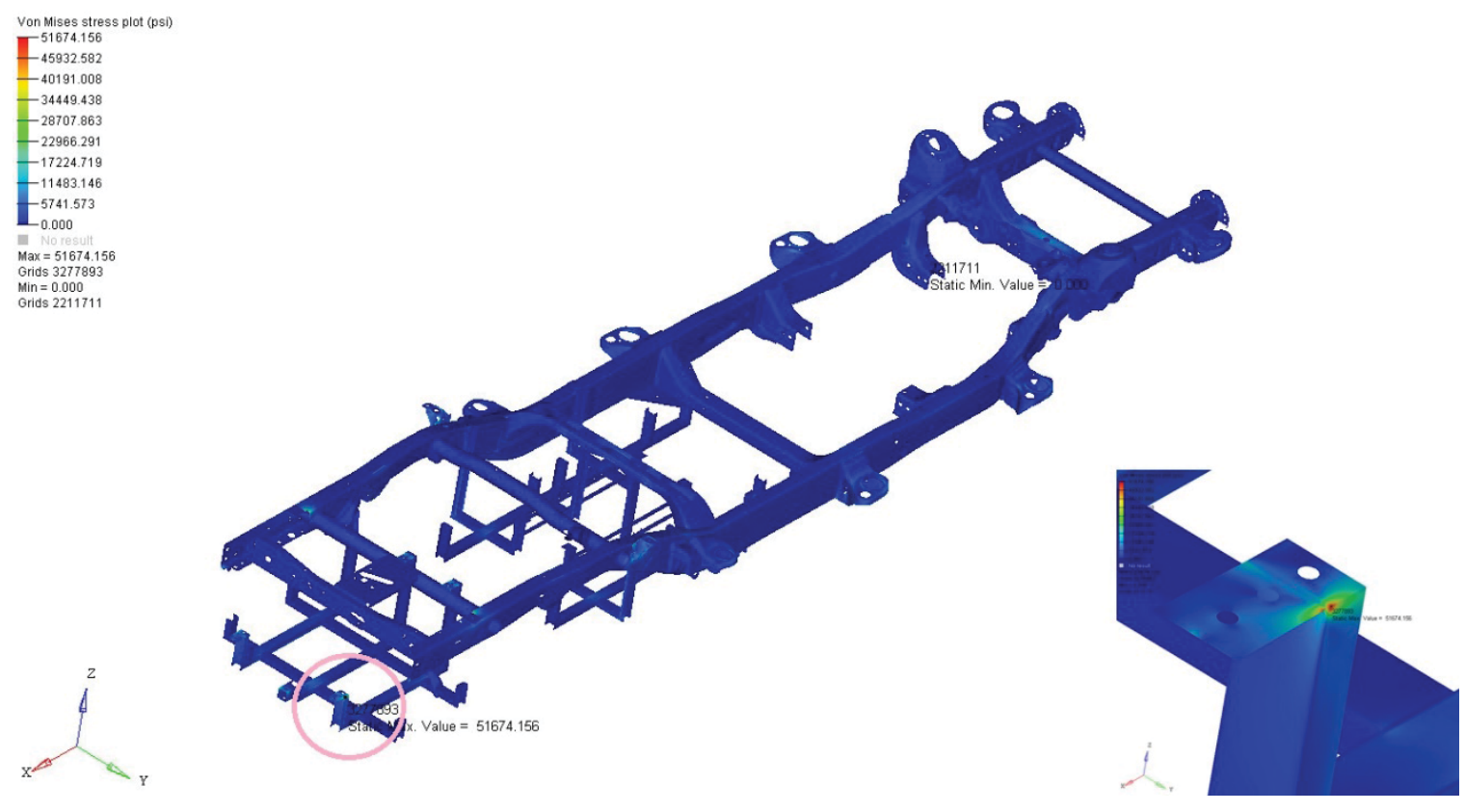

Figure 31. Von Mises stress (psi) plot of the frame with modified configuration

Figure 31 shows the von Mises stress plot along with the location of the maximum stress in the frame with modified configuration. The value of the maximum stress is 51.67 $\mathrm{ksi}$, and it is located in the back bracket, in the member which is to be connected to the trailer hitch receiver. The material used for the brackets has the yield strength of $36.3 \mathrm{ksi}$ and ultimate tensile strength ranging from $58 \mathrm{ksi}$ to $79.8 \mathrm{ksi}$. Hence, the stress generated is crossing the yield limit of the material, giving 0.7 factor of safety. Appendix A.1-A.3 shows the results of individual sub-assemblies for the modified configuration of the frame. 


\subsection{Result Table}

Table 4. Result summary for section 3.8

\begin{tabular}{|c|c|c|c|c|c|c|c|}
\hline $\begin{array}{l}\text { Sr. } \\
\text { No. }\end{array}$ & $\begin{array}{l}\text { Frame } \\
\text { Config- } \\
\text { uration }\end{array}$ & Component & Material & $\begin{array}{l}\text { Maximum } \\
\text { Displacement } \\
\text { (inch) }\end{array}$ & $\begin{array}{l}\text { Maximum } \\
\text { von Mises } \\
\text { stress } \\
(\mathrm{ksi})\end{array}$ & $\begin{array}{l}\text { Yield } \\
\text { strength } \\
\text { (ksi) }\end{array}$ & $\begin{array}{l}\text { Factor } \\
\text { of } \\
\text { safety }\end{array}$ \\
\hline 1 & Original & Frame & $\begin{array}{l}\text { GM } \\
980 X\end{array}$ & 0.027 & 47.37 & 55 & 1.161 \\
\hline \multirow{3}{*}{2} & \multirow{3}{*}{ Modified } & Frame & $\begin{array}{l}\text { GM } 980 \\
\text { X }\end{array}$ & 0.04 & 47.27 & 55 & 1.164 \\
\hline & & $\begin{array}{l}\text { Side } \\
\text { brackets }\end{array}$ & $\begin{array}{l}\text { A36 } \\
\text { mild } \\
\text { steel }\end{array}$ & 0.075 & 10.906 & 36.3 & 3.329 \\
\hline & & $\begin{array}{l}\text { Back } \\
\text { bracket }\end{array}$ & $\begin{array}{l}\text { A36 } \\
\text { mild } \\
\text { steel }\end{array}$ & 0.111 & 51.674 & 36.3 & 0.703 \\
\hline
\end{tabular}




\section{Discussion}

\subsection{Original configuration}

The FEA of the original configuration of the frame gave a maximum displacement of 0.027 inches and a maximum von Mises stress of 47.375 ksi. Since the entire structure is large in size and dense with multiple mounts, the recorded displacement is not significant to cause failure in the structure. However, the factor of safety of 1.16 gives very little tolerance when it comes to modifications requiring addition in attached weight. On close observation, it is clear that the stress plot shows $90-95 \%$ of the structure has very little stresses.

\subsection{Modified configuration}

Analysis of the modified configurations provided very high displacements and stresses. Upon observation of the exploded view of the assembly, studies of three main components were conducted. The three components separately analyzed were the frame, two side brackets, and the back bracket. Figure 32 and 33 in section A.1 show the displacement and von Mises stress plot, respectively, of the frame. The new loading of the frame actually improved the factor of safety by a small amount. Most stress contours were similar to that of the original configuration. Hence, the frame is capable of handling the increased load.

Figure 34 and 35 show the displacement and stress plots of the two side brackets respectively. The factor of safety generated is 3.33, which shows that the structure is safe. Figure 36 and 37 show the displacement and stress plots of the back bracket, respectively. It can be seen that both the maximum displacement and maximum stress is occurring in the trailering side. The approximation of considering the trailering hitch to be a rigid 
member could be the main reason for the generation of high stress. Total transfer of the load from the frame to the bracket is causing the material to go into the plastic phase. The trailering hitch receiver acts similar to the other cross-members in the frame and is mainly used to handle high loads in the range of GVWR. Being an elastic member, it absorbs some load before transferring it to the frame. Inclusion of the trailering hitch receiver in the analysis will reduce the maximum stress and increase the factor of safety. It is not possible to guarantee whether the improvement in the factor of safety will avoid the current back bracket to go plastic. A non-linear analysis is needed to study the behavior of the back bracket, when high stresses exceeding the elastic limit are generated. 


\section{Conclusion}

Successful integration of the non-cylindrical CNG fuel tank on the vehicle underbody would solve the issue of lack of space in the vehicle cargo. Coupled with the on-going growth in the CNG fuelling stations and maintenance infrastructure, CNG would prove to be a good alternative to gasoline. Advantages of using a CNG powered vehicle would include reduction in emission of harmful exhaust gases like carbon monoxide, carbon dioxide and hydro-carbons, less fuel consumption and reduced dependency on a single fuel (Aslam et al., 2006).

The study of the vehicle frame using finite element method shows that integration of these tanks is possible with the current designs. The analysis of the original frame showed that the frame can handle extended loads due to majority of low stress zones and the factor of safety of 1.16. The design of brackets, even though not finalized, is a robust structure with a simple design. Loading of the new tanks do not affect the factor of safety of the frame which suggests that for phase I the devised modifications will work just fine. However for phase II dynamic load cases will be required to validate the design of the brackets.

\subsection{Recommendation for future work}

Redesigning the bracket with improved support structure would help improve the weight carrying capacity of the bracket. Weight of the bracket should be kept under control, as increasing it would induce increased stresses in the frame. Another solution could be the use of a different material instead of A36 steel. Using the finite element method, the mounting of the back bracket should be simulated as per reality, with the inclusion of the trailer hitch receiver in future simulations. Also, instead of conducting a simple linear static 
analysis, a material non-linear analysis could be conducted on the three brackets to establish their behavior after entering the plastic phase. Using the results from the original configuration analysis, the low stress regions could be accessed as the potential locations for any further modifications. Also, it is recommended to perform a full frame dynamic analysis to study the deformation pattern of the brackets in case of an impact with outside obstacles. 


\section{References}

Ahn, J., Jeong, G., \& Kim, Y. (2008). A forecast of household ownership and use of alternative fuel vehicles: A multiple discrete-continuous choice approach. Energy Economics, 30(5), 2091-2104. doi: http://dx.doi.org/10.1016/j.eneco.2007.10.003

Altair University. (2011). 2-D Meshing. Hyperworks Practical Aspects of Finite Element Simulation, 147-182. Troy, Michigan: Altair Engineering. Retrieved on June 22, 2015, from ftp://ftp.altair-gmbh.de/pub/edu/protected/Student_Guide_011912.pdf

Aslam, M. U., Masjuki, H. H., Kalam, M. A., Abdesselam, H., Mahlia, T. M. I., \& Amalina, M. A. (2006). An experimental investigation of CNG as an alternative fuel for a retrofitted gasoline vehicle. Fuel, 85(5-6), 717-724. doi: http://dx.doi.org/10.1016/j.fuel.2005.09.004

General Motors. (2013, May). 2014 Silverado Chassis is Foundation for Greater Capability. Retrieved June 22, 2015, from

http://media.gm.com/media/us/en/chevrolet/news.detail.html/content/Pages/news/us/en/2 013/May/Silverado-May-5/0505-silverado-chassis.html

General Motors. (2015). THE 2015 SILVERADO 1500 catalog. Retrieved on June 22, 2015, from http://www.chevrolet.com/content/dam/Chevrolet/northamerica/usa/nscwebsite/en/Home/ Help\%20Center/Download\%20a\%20Brochure/02_PDFs/GMXS15CT400_2015\%20Silv erado\%20LD\%20Catalog_REPRINT.pdf

Kilian, L. (2010, April). Explaining fluctuations in gasoline prices: a joint model of the global crude oil market and the U.S. retail gasoline market. The Energy Journal, 31(2), 87+. Retrieved on June 30, 2015, from 
http://go.galegroup.com/ps/i.do?id=GALE\%7CA224334771\&v=2.1\&u=lom_mtu\&it=r\& $\mathrm{p}=\mathrm{AONE} \& \mathrm{sw}=\mathrm{w} \& \mathrm{asid}=\mathrm{b} 2185 \mathrm{c} 1590546 \mathrm{f} 73401086 \mathrm{c} 6 \mathrm{c} 70 \mathrm{c} 55 \mathrm{cb}$

Matweb, LLC. (2015). ASTM A36 Steel, plate. Retrieved June 22, 2015, from

http://www.matweb.com/search/datasheet.aspx?matguid=d1844977c5c8440cb9a3a967f8 $\underline{909 c 3 a}$

Rashid, M. (1977). GM 980X - Potential Applications and Review. SAE Technical Paper 770211, 1977, doi: 10.4271/770211.

Roesler, J., Harders, H., \& Baeker, M. (2007). Plasticity and failure. Mechanical behaviour of engineering materials metals, ceramics, polymers, and composites, 63-92. Berlin: Springer.

Totten, G. (2006). Steel Nomenclature. Steel heat treatment equipment and process design, (2), 24-27. Boca Raton, FL: Taylor \& Francis. Retrieved on June 22, 2015, from https://books.google.com/books?hl=en\&lr=\&id=_WkyJv9MOpEC\&oi=fnd\&pg=PA1\&d $q$ =sae+hsla+steel+grades+nomenclature\&ots=7CiIOnbIIp\&sig=e_IpZqf234n6iFxJ0OVH cgjLuVY\#v=onepage\&q=sae\%20hsla\%20steel\%20grades\%20nomenclature\&f=false 


\section{Appendix}

\section{A.1 Isolated modified frame}
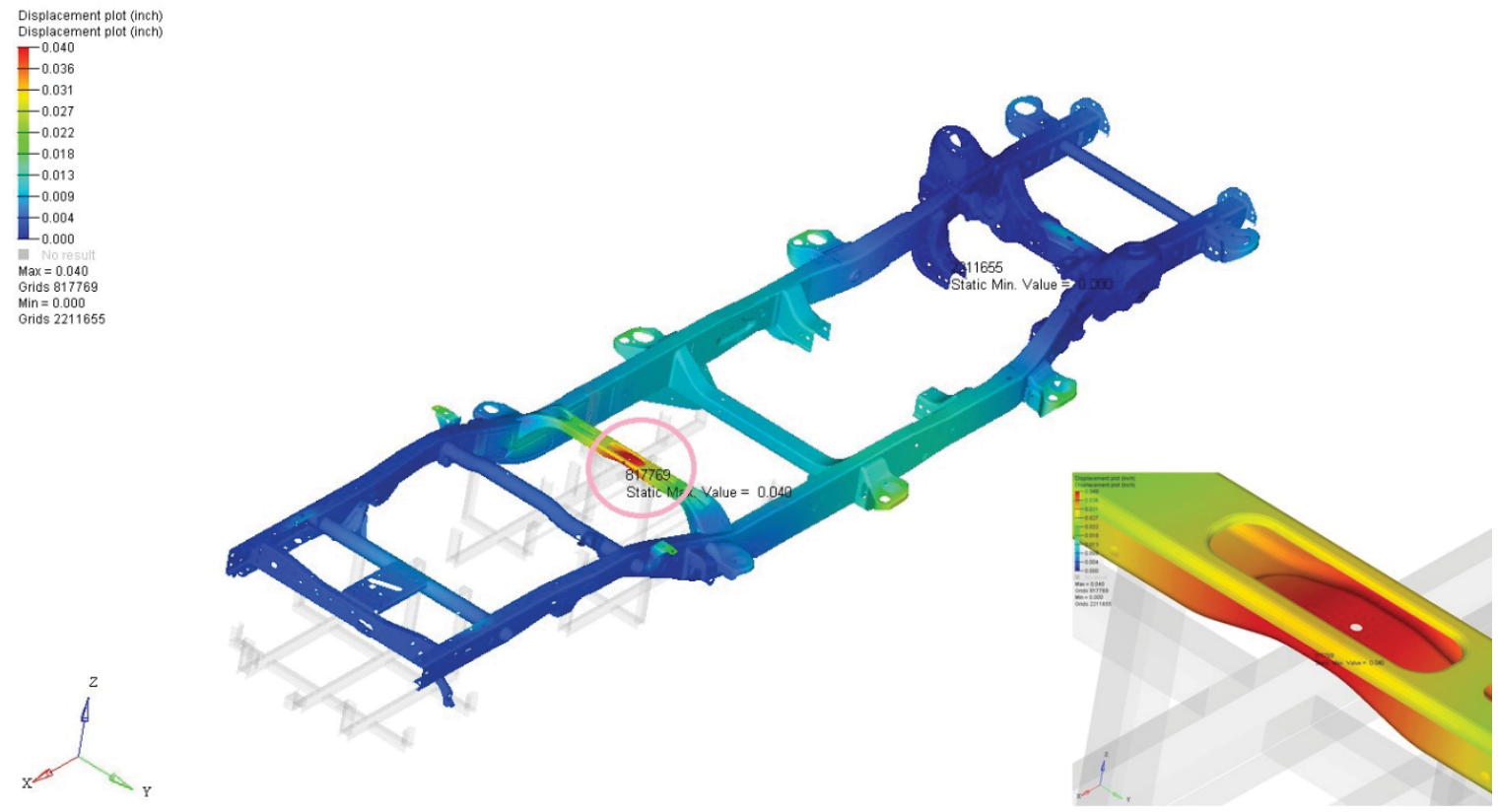

Figure 32. Displacement (inch) plot of the isolated frame with modified configuration
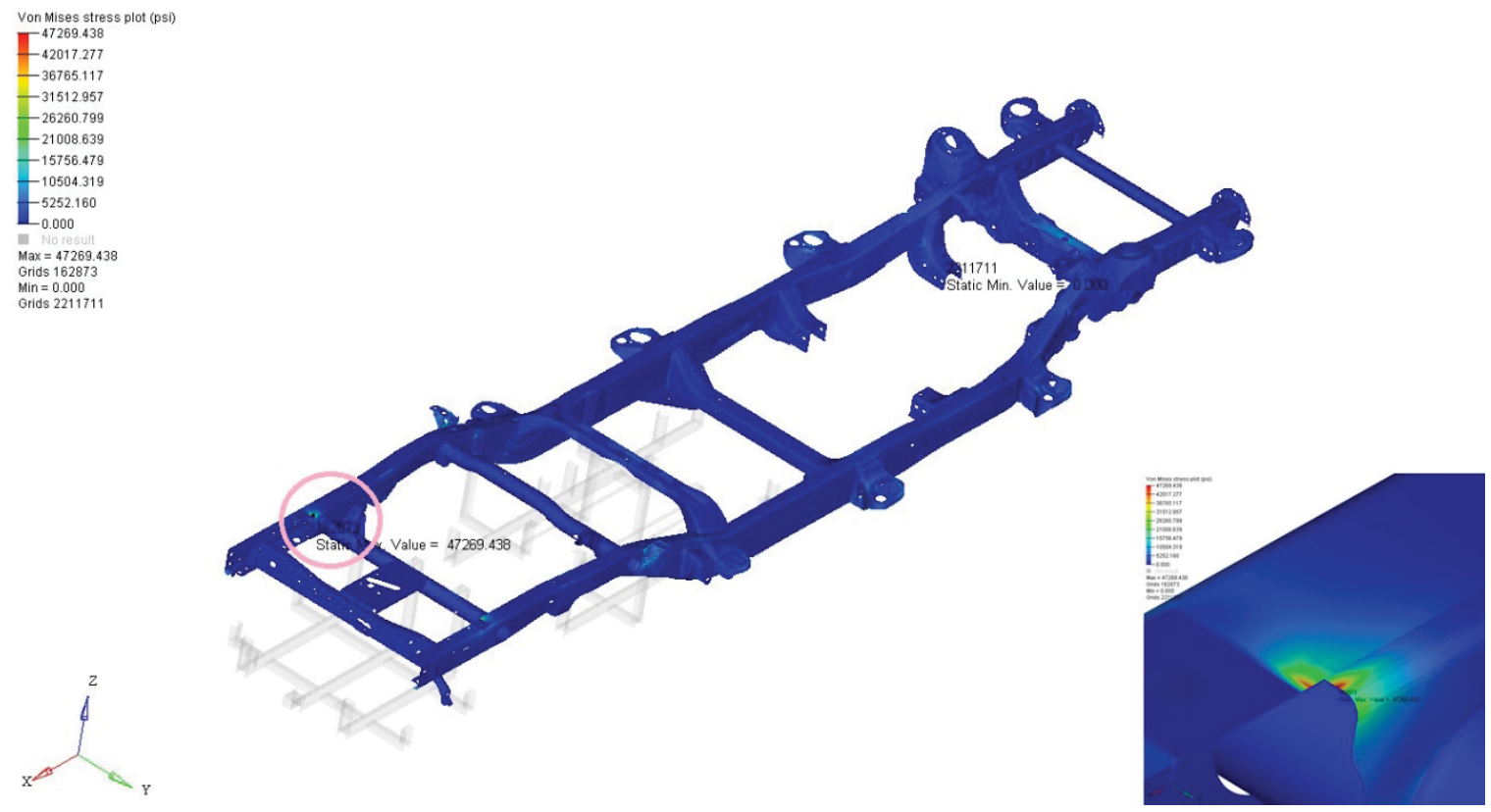

Figure 33. Von Mises stress (psi) plot of the isolated frame with modified configuration 
A.2 Isolated side brackets
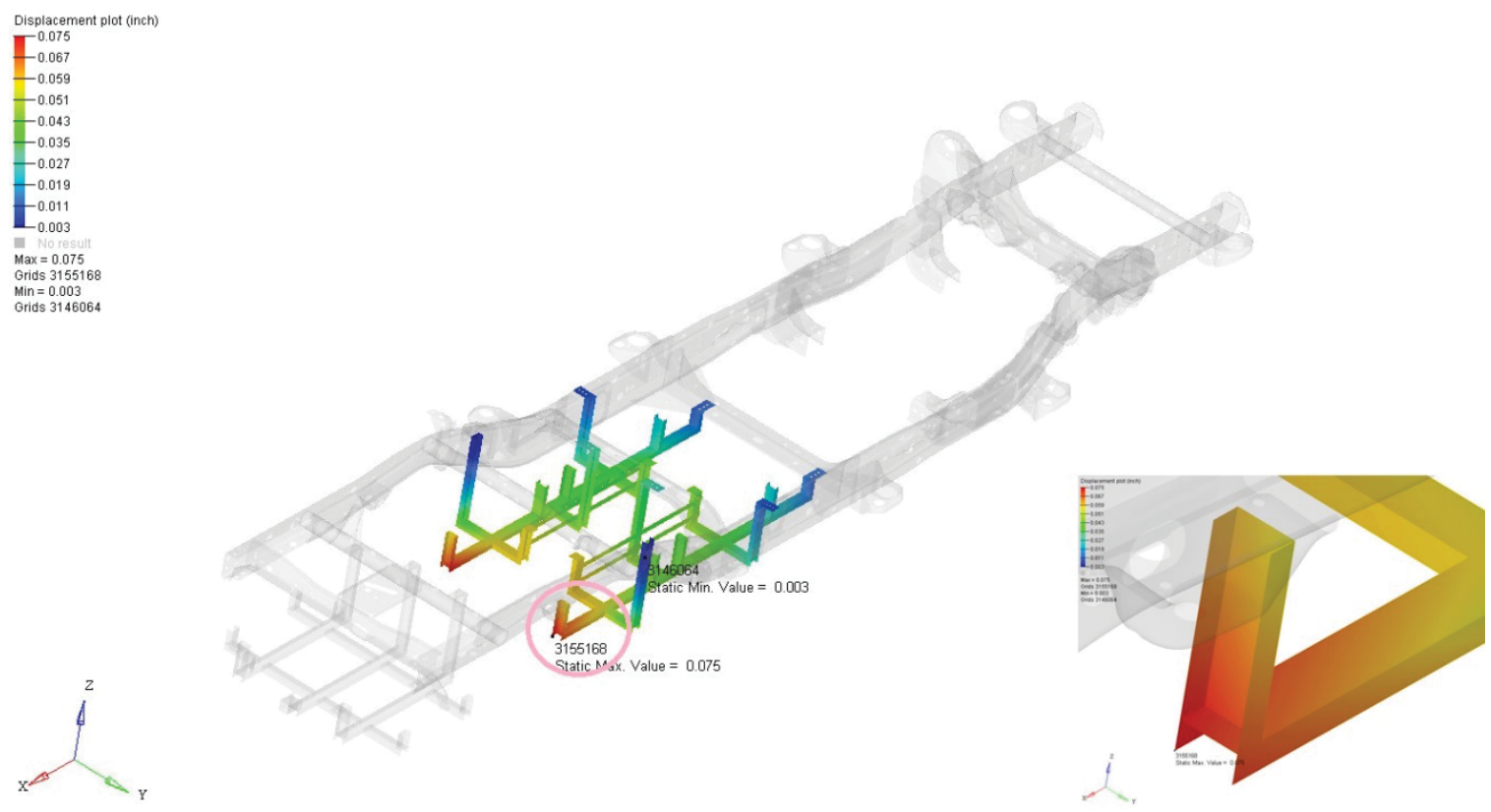

Figure 34. Displacement (inch) plot of the isolated side brackets
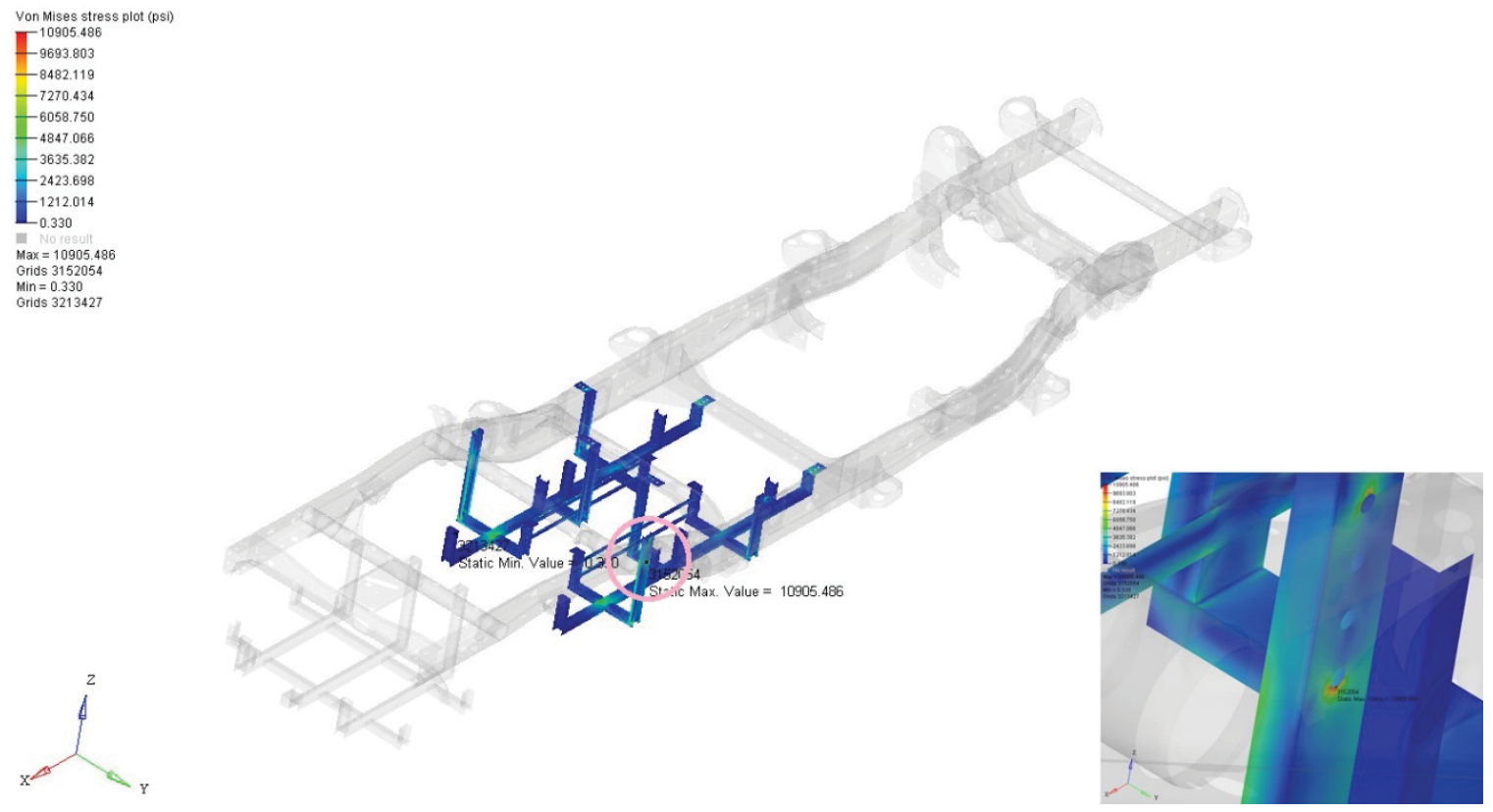

Figure 35. Von Mises stress (psi) plot of the isolated side brackets 


\section{A.3 Isolated back brackets}
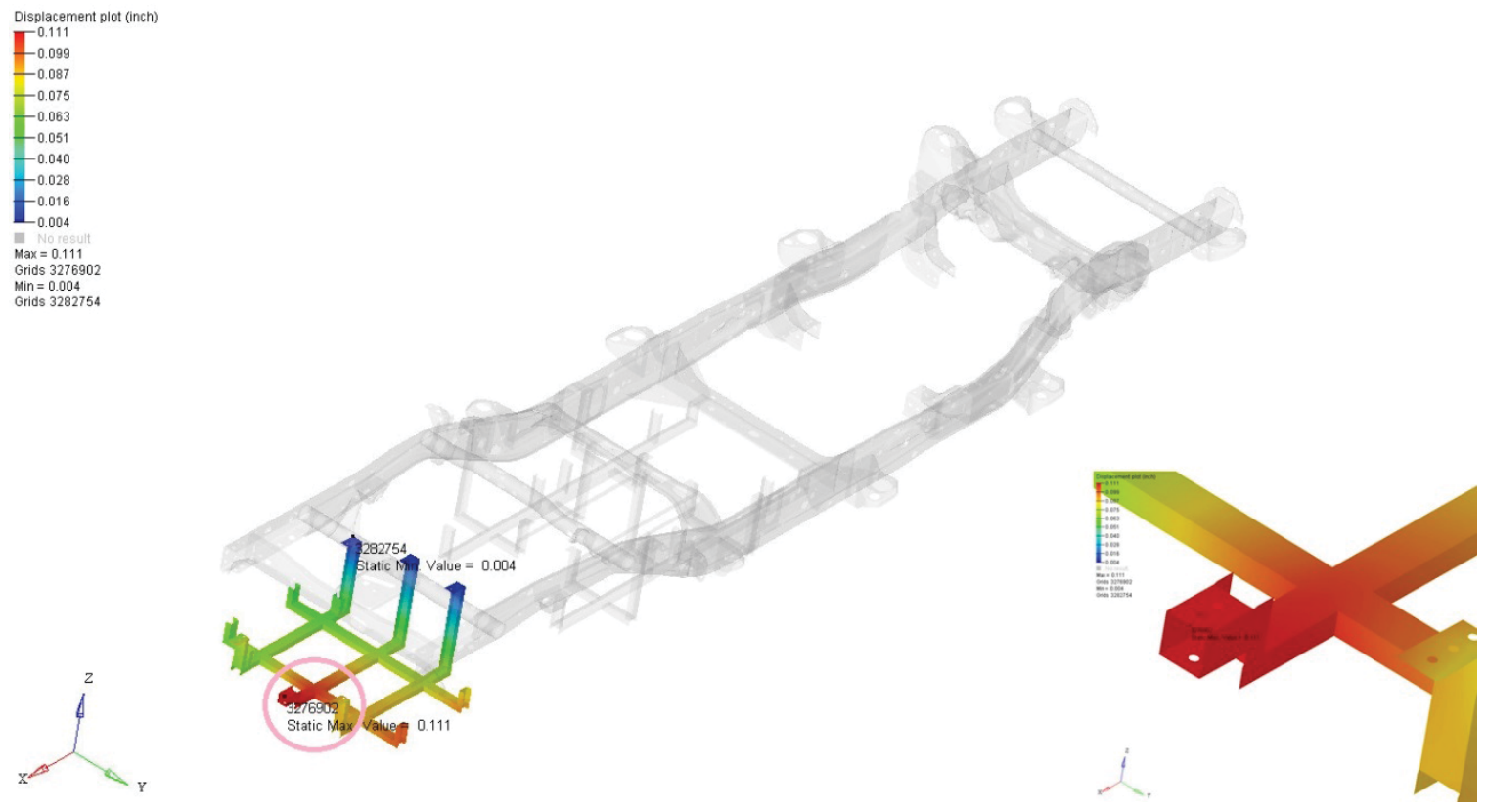

Figure 36.Displacement (inch) plot of the isolated back bracket
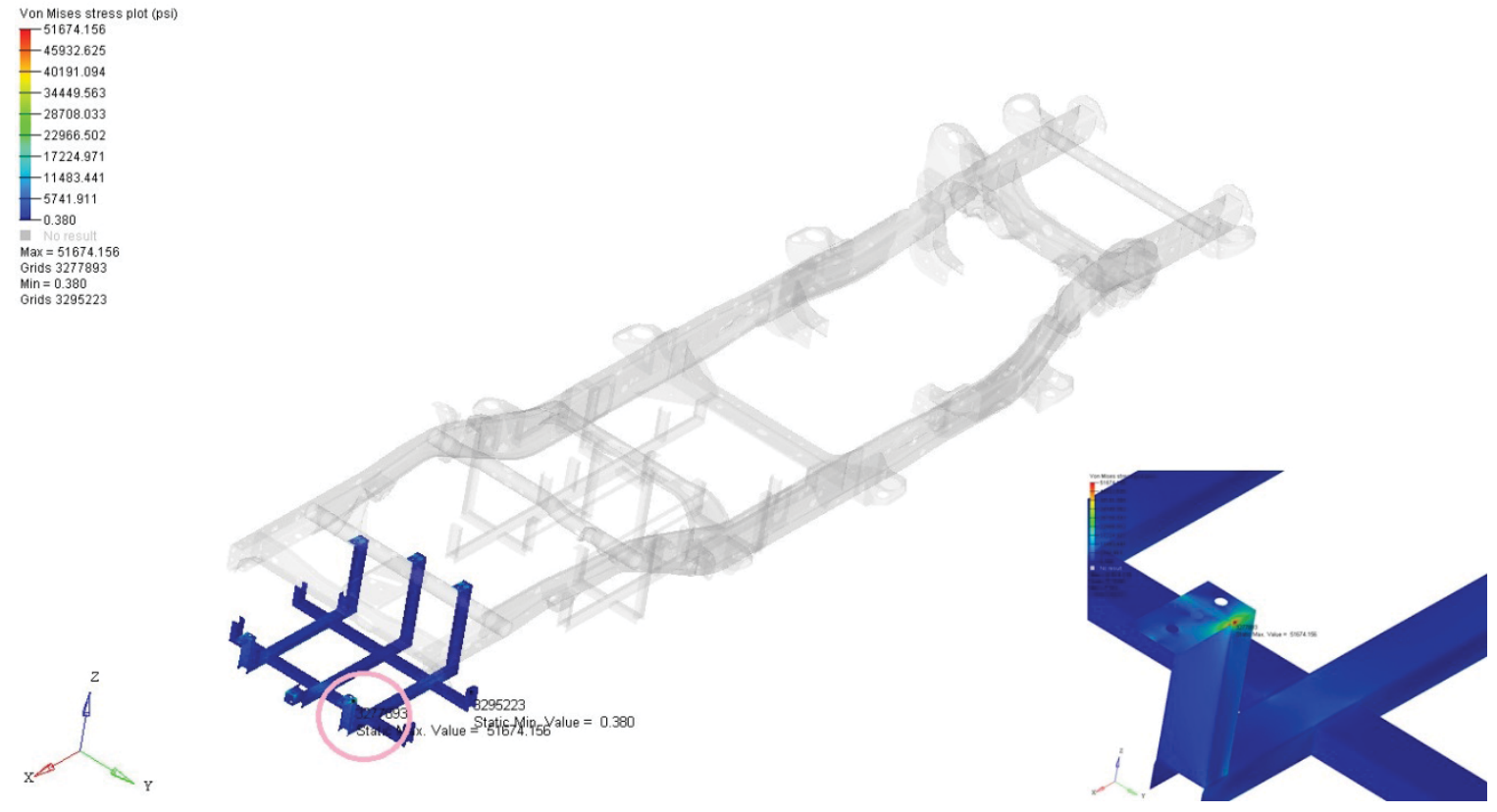

Figure 37. Von Mises stress (psi) plot of the isolated back bracket 